\title{
Nanotoxicity: Dimensional and Morphological Concerns
}

\author{
Mohmmad Younus Wani, ${ }^{1}$ Mohd Ali Hashim, ${ }^{2}$ Firdosa Nabi, ${ }^{3}$ and Maqsood Ahmad Malik ${ }^{2}$ \\ ${ }^{1}$ Centre for Interdisciplinary Research in Basic Sciences, Jamia Millia Islamia (Central University), New Delhi 110025, India \\ ${ }^{2}$ Department of Chemical Engineering, University Malaya, 50603 Kuala Lumpur, Malaysia \\ ${ }^{3}$ Department of Chemistry, University Malaya, 50603 Kuala Lumpur, Malaysia
}

Correspondence should be addressed to Maqsood Ahmad Malik, maqsoodchem@gmail.com

Received 30 September 2010; Revised 14 December 2010; Accepted 3 January 2011

Academic Editor: Vicki H. Grassian

Copyright (C 2011 Mohmmad Younus Wani et al. This is an open access article distributed under the Creative Commons Attribution License, which permits unrestricted use, distribution, and reproduction in any medium, provided the original work is properly cited.

\begin{abstract}
Nanotechnology deals with the construction of new materials, devices, and different technological systems with a wide range of potential applications at the atomic and molecular level. Nanomaterials have attracted great attention for numerous applications in chemical, biological, and industrial world because of their fascinating physicochemical properties. Nanomaterials and nanodevices are being produced intentionally, unintentionally, and manufactured or engineered by different methods and released into the environment without any safety test. Nantoxicity has become the subject of concern in nanoscience and nanotechnology because of the increasing toxic effects of nanomaterials on the living organisms. Nanomaterials can move freely as compared to the largesized particles; therefore, they can be more toxic than bulky materials. This review article delineates the toxic effects of different types of nanomaterials on the living organisms through different sources, like water, air, contact with skin, and the methods of determinations of these toxic effects.
\end{abstract}

\section{Introduction}

Hundreds of researchers all over the world are engaged in delving deep into the field of nanotechnology. Nanoscience and nanotechnology promise for creating new materials with enhanced properties and potential applications $[1,2]$. The properties of these various types of intentionally produced nanomaterials and nanoparticles enable potential application in commercial, medical, environmental sectors and so forth. Nanoparticles are said to be central to many natural processes [3-5]. Nanoparticles are present in the environment from both natural and anthropogenic sources. Examples of natural nanoparticles include volcanic ash, ocean spray, and mineral composites. Anthropogenic nanoparticles can be either incidental or engineered. Manufactured or engineered nanoparticles have great diversity in shape and function as seen in large variety of carbon nanotubes, fullerenes, polymers, nanoribbons and dendrimers. Many nanoparticles have unique properties, such as being optically transparent and distinctive surface properties. Many concerns have risen regarding the disruption of many critical biological processes by many engineered nanomaterials. Various nanomaterials have proven to be toxic to humans, animals, and environmental systems [6]. Yet nanomaterials are being manufactured commercially and released into the environment without any health and safety testing or environmental impact assessment. Despite this lack of oversight, there are hundreds of products [7-9] containing nanomaterials that are commercially available, including sunscreens, cosmetics, foods, fertilizers, clothing, industrial catalysts, fuel cells, sports equipment, computer and television screens, and medical equipment.

The negative health impacts of exposure to ultrafine particles in air pollution, coal and silica dust, welding fume, asbestos, and other human-made mineral fibers have all been studied extensively in the past. The existing body of toxicological literature [10] suggests clearly that nanoparticles may have a greater risk of toxicity than larger particles. This body of evidence has been sufficient for the world's oldest scientific organization to warn that we should not release consumer products containing nanomaterials until we have vastly improved requirements for safety testing [11]. The fundamental properties of matter change at the nanoscale. The physicochemical properties and applications 
of nanoparticles are quite different from those of larger particles of the same substance. The chemical reactivity and biological activity of nanomaterials are often greater than those of larger-sized particles [12]. The smaller a particle, the greater is its surface area to volume ratio and the higher its chemical reactivity and biological activity [13]. Size is therefore a key factor in determining the potential toxicity of a particle. The greater chemical reactivity of nanoparticles results in increased production of reactive oxygen species (ROS), including free radicals [14]. ROS production has been found in a diverse range of nanomaterials including carbon fullerenes, carbon nanotubes, and nanoparticle metal oxides [15]. ROS and free radical production is one of the primary mechanisms of nanoparticle toxicity; it may result in oxidative stress, inflammation, and consequent damage to proteins, membranes, and DNA [16]. Other factors influencing toxicity include shape, chemical composition, surface structure, surface charge, aggregation and solubility [17]. Nanoparticles are much more mobile than larger-sized particles. They are more readily taken up by the human body and are able to cross membranes and gain access to cells, tissues, and organs that larger-sized particles normally cannot [18]. Unlike larger particles, nanoparticles may be transported within cells and be taken up by cell mitochondria [19] and the cell nucleus [20], where they can induce major structural damage to mitochondria $[21,22]$, cause DNA mutation [23], and even result in cell death [24]. There is often no relationship between the toxicity of a nanoparticle and the toxicity of a larger particle of the same substance; one cannot assume that substances known to be benign at a larger scale will remain safe at the nanoscale. Essentially, while not all nanoparticles are toxic, the existing evidence indicates that nanoparticles pose greater risks of toxicity than larger-sized particles of the same substance.

\section{Evidence for Toxicity of Nanomaterials}

The increase in lung inflammation, oxidative stress, negative impacts in other organs, and the cardiovascular system is by the respiratory exposure to implanted or inhaled engineered nanoparticles [25]. Irrespective of their chemical composition, engineered nanoparticles are recognized to be potent inducers of inflammatory lung injury in humans [26]. It has been noted that constant lung inflammation because of occupational exposure to high levels of nanoparticles could lead to diseases such as fibrosis and cancer [27]. The exposure of nanoscale fibres (e.g., carbon nanotubes) at workplace is of obvious concern given the well-established association of other inhalable fibres such as asbestos with the risk of lung inflammation and prolonged exposure may later cause cancer [28]. This has prompted calls for toxicity testing of carbon nanotubes to be benchmarked against that of asbestos fibres $[29,30]$. It is very difficult to distinguish between exposure to nanoscale and larger-sized particles. The particle surface area is the better predictor of toxicity for nanoscale particles [31] but most existing exposure standards are based on weight-based measures. Recently it was investigated that exposure to carbon nanotubes based on the existing permissible (weight-based) occupational exposure limit for graphite particles found that carbon nanotubes resulted in inflammation and reduced pulmonary function and the early onset of fibrogenesis [32]. On weight-based study carbon nanotubes are found to be more toxic than ultra-fine carbon black or silica dust. Recent investigations have shown that if workers are exposed to respirable SWCNT (single-walled carbon nanotubes) particles at the current PEL (permissible exposure limit) (for graphite particles), they may be at risk of developing some lung lesions [33]. Carbon nanotubes have been shown to cause the death of kidney cells and to inhibit further cell growth by decreasing cellular adhesive ability [34]. Nanomaterials can gain access to the blood stream following inhalation and ingestion, possibly, through skin absorption, especially if the skin is damaged [35]. These nanomaterials in the blood stream can move through the body and are taken up by organs and tissues including the brain, heart, liver, kidneys, spleen, bone marrow, and nervous system [36]. Nanoparticles have been proven toxic to human tissue and cell cultures, resulting in increased oxidative stress, inflammatory cytokine production, and cell death [37]. The distribution of particles within the body, and the accumulation of a specific type of particle in a particular part of the body, is dependent on the particle's size and surface characteristics [38]. The major distribution sites and the target organs for nanoparticles are yet unknown; however it appears that liver may be the target organ, followed by the spleen $[39,40]$. The studies have shown that in case of lung diseases, the accumulation of even harmless foreign matter may impair its function and result in harm [41]. Even low levels of fullerene (buckyballs) exposure have been shown to be toxic to human lung cells $[42,43]$ and have been found to cause brain damage in fish, kill water fleas and have bactericidal properties [44-47]. Researchers are investigating the ability of surface coatings and modifications to make nanomaterials safe but the studies have shown that these protective qualities of surface coatings are shortlived because both surface coatings and modifications can be weathered over a 1-4-hour period by exposure to the oxygen in air, or by ultraviolet irradiation [48]. It has also been investigated that ingested coatings could be metabolized to expose the core harmful nanomaterial [49].

\subsection{Effects of Nanoparticles on Various Systems}

2.1.1. Pulmonary Effects. The nanoparticles have ability to induce the lung injuries because of their small size, a large surface area, and an ability to generate reactive oxygen species (ROS). The short-term pulmonary toxicity studies in rats with ultrafine and fine carbon black, nickel, and $\mathrm{TiO}_{2}$ particles have established enhanced lung inflammatory strength of the ultrafine particles in comparison to fine-sized particulates of similar composition [50-52]. It is observed that the particle-overload effects in rats resulted in the development of exaggerated lung responses, characterized by increased and persistent levels of pulmonary inflammation, failed clearance, cellular proliferation, fibroproliferative effects, and inflammatory-derived mutagenesis, and this ultimately results in the development of lung tumours. Factors that are likely to influence the pulmonary toxicity of 
nanoparticles are particle size, number, surface dose, surface coatings on particles, degree of aggregation, surface charges, and method of particle synthesis [46, 53-57].

2.1.2. Effects on Reticuloendothelial Systems. The reticuloendothelial system in the liver is exposed to all nanoparticles absorbed from the gastrointestinal tract into the cardiovascular system, since all blood exiting the gastrointestinal tract goes into the hepatic portal vein that directly diffuses through the liver. Low toxicity nanoparticles such as carbon black and polystyrene stimulate the macrophages via reactive oxygen species and calcium signaling, to make proinflammatory cytokines such as tumour necrosis factor alpha [58]. The hepatocyte function and bile formation is inhibited by oxidative stress, while proinflammatory cytokines are also associated with the pathology of liver disease.

2.1.3. Cardiovascular Effects. The cationic nanoparticles, including gold and polystyrene, have shown to cause hemolysis and blood clotting, while usually anionic particles are quite nontoxic. High exposures to diesel exhaust particles (DEPs) by inhalation caused altered heart rate in hypertensive rats interpreted as a direct effect of DEP on the pacemaker activity of the heart [59]. Exposure to single-walled carbon nanotubes has also resulted in cardiovascular effects [60]. It has been investigated that the ultrafine carbon black instilled into the blood induces platelet accumulation in the hepatic microvasculature of healthy mice in association with prothrombotic changes on the endothelial surface of the hepatic microvessels [61].

2.1.4. Central Nervous System Effects. The nanoparticles inhaled can gain access to the brain by means of two different mechanisms, namely, transsynaptic transport after inhalation through the olfactory epithelium and uptake through the blood-brain barrier [62, 63]. A number of pathologies, including hypertension and allergic encephalomyelitis, however have been associated with increased permeability of the blood brain barrier to nanoparticles in experimental setups. The nanoparticle surface charges have been shown to alter blood-brain integrity and need consideration as to their role in brain toxicity and brain distribution. Nanoparticles have been shown to induce the production of reactive oxygen species [64] and oxidative stress [65] and oxidative stress has been implicated in the pathogenesis of neurodegenerative diseases such as Parkinson's and Alzheimer's.

2.1.5. Dermatological Effects. Particles with a size of approximately $50-500 \mathrm{~nm}$ are widely used in cosmetic products of concentration of nanoparticles less than $3 \%$. Because of their scattering properties, nanoparticles increase the optical pathway of UV photons entering the upper part of the horny layer. In this way, more photons are absorbed by the stratum corneum and by the applied organic filter substances. Dermatological effects of these nanoparticles are mainly focused on the question whether these particles are able to penetrate into or through the skin. In vitro studies have shown that multiwalled carbon nanotubes are capable of localizing within and initiating an irritation response in human epidermal keratinocytes, which are a primary route of occupational exposure [66, 67].

2.1.6. Effect on Other Biological Systems. The change in the structural and physicochemical properties of nanoparticles with a decrease in size could be responsible for numerous material interactions that could lead to toxicological effects [68]; for example, shrinkage in size may create discontinuous crystal planes that increase the number of structural defects as well as disrupt the electronic configuration of the material and give rise to altered electronic properties (Figure 1). These changes could establish specific surface groups that could function as reactive sites. Chemical composition of the materials is particularly responsible for these changes and their importance. The surface groups can make nanoparticles hydrophilic or hydrophobic, lipophilic or lipophobic, or catalytically active or passive. These surface properties can lead to toxicity by the interaction of electron donor or acceptor active sites (chemically or physically activated) with molecular oxygen $\left(\mathrm{O}_{2}\right)$ and electron capture can lead to the formation of the superoxide radical, which generate additional reactive oxygen species (ROS) through Fenton chemistry (Figure 1). Single-component materials and presence of transition metals on the surface can participate in the formation of such active sites [68]. According to the hierarchical oxidative stress hypothesis, the lowest level of oxidative stress is associated with the induction of antioxidant and detoxification enzymes. It has been demonstrated that organic DEP (diesel exhaust particle) extracts induce a dose-dependent decrease in the GSH/GSSG ratio (Reduced glutathione, most commonly called glutathione or GSH; glutathione disulfide or oxidized glutathione (GSSG)) in macrophage cell lines in parallel with a linear increase in the number of newly expressed proteins. More than half of these proteins are suppressed in the presence of thiol agent $\mathrm{N}$ acetylcysteine (NAC) which has antioxidant activity. These proteins included antioxidant enzymes, for example, HO-1 and catalase, as well as proteins that play a role in pulmonary inflammation, namely, p38MAPK and Rel A. It has been suggested that organic DEP chemicals induce a hierarchical oxidative stress response, which is reflected by the type of proteins being expressed [69]. The stress-activated protein kinases play an important role in the expression and transcriptional activation of several transcription factor AP1 proteins and are often linked to proinflammatory and injurious cellular responses. This transcriptional activation of cytokine and chemokine genes is also included. These proinflammatory effects constitute a second tier or a superimposed level of oxidative stress, and that proteins that are induced or activated in this zone play a role in the proinflammatory and adjuvant effects of DEP in the lung.

The superimposed level of oxidative stress is cytotoxicity, including the initiation of programmed cell death. This effect is dependent on mitochondrial perturbation, including effects on the mitochondrial membrane potential and cytochrome $\mathrm{c}$ release. A number of responses at each level of oxidative stress have now been successfully incorporated as screening assays for toxicological effects of ambient PM 


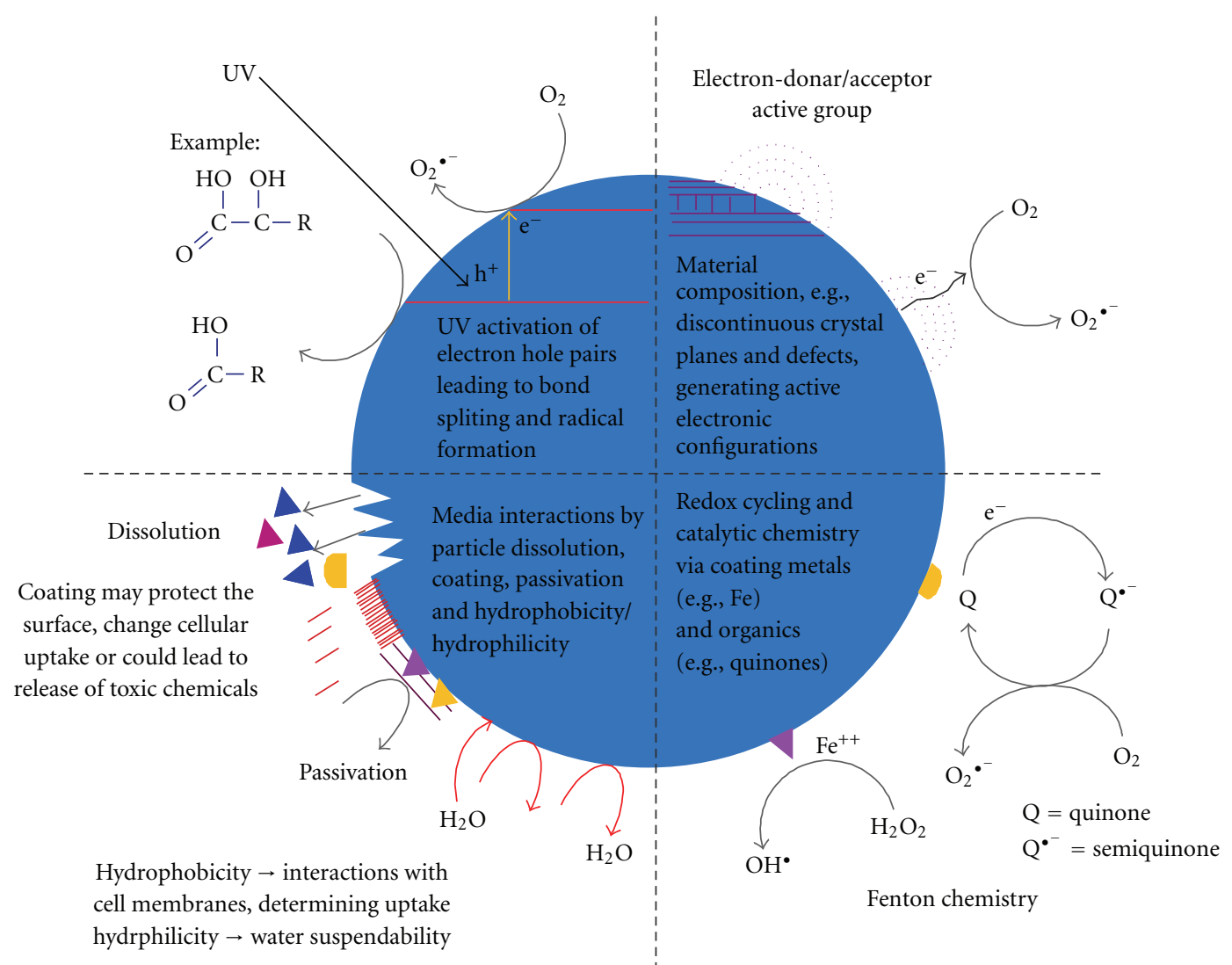

FIGURE 1: Effect of reactive oxygen species in cells.

in vivo, for example, increased expression of antioxidant enzymes and cytokines in the lungs of exposed animals. Particle size characterization and physical characteristics, together with in vitro assays for ROS and oxidative stress plus in vivo markers of oxidative stress, are an example of a predictive paradigm for toxicity screening. Similar paradigms can be developed for engineered nanomaterials. In another set of experiments, it was observed that carbon black nanoparticles stimulate the entry of extracellular calcium into adhered primary rat alveolar macrophages on an individual cell basis [69]. Carbon black nanoparticles were observed to increase the DNA binding of the transcription factor AP1 in rat alveolar macrophages, and p50 and p65 nuclear localization in the human monocytes. It has been observed that calcium is involved in the regulation of the cytokine. It has been suggested that ROSs are partly responsible for driving the nanoparticle-induced calcium response in macrophages, as this response was inhibited by antioxidants. Various studies have been carried out to investigate the adverse effects of nanoparticle on the biological systems $[18,21,26,42,46,65]$ and the interaction of nanoparticles with biological systems is represented in Figure 2. It has been demonstrated that carbon black nanoparticles produce its increased inflammatory effects via mechanisms other than the leaching of soluble components from the particle surface. Transition metals are an important source of free radicals, which are important in PM10-stimulated lung inflammation. Therefore, it is clear that nanoparticles may exert their increased proinflammatory effects, at least in part, by modulating intracellular calcium.

\section{Toxicity of Nanomaterials on Embryonic Cells}

The toxicity of nanomaterials on embryonic cells using fluorescence correlation spectroscopy has been recently reported [70]. Live embryonic chicken's blood stream has been used in this study to assess the behavior of nanoparticles [70]. Fluorescence correlation spectroscopy provides insight into the aggregation state of fluorescent nanoparticles. It has been observed that in smaller blood vessels more aggregation takes place than in larger blood vessels, particularly for nanoparticles with carboxylate groups on their surfaces. These findings are important because aggregation state likely influences nanoparticle accumulation in angiogenic tissues. By using fluorescence correlation spectroscopy, it is possible to measure the loss of nanoparticles from the blood streams of live embryos. The kinetics of loss could be correlated with surface charge, chemistry, and size and the rate constants inputted into predictive models. Recent work indicates that once in the bloodstream of mature animals, renal clearance will occur only for nanoparticles smaller than $5 \mathrm{~nm}$ in lateral dimension [70]. Additionally, nanoparticles are proving to be effective delivery agents for directing therapeutic cargo 


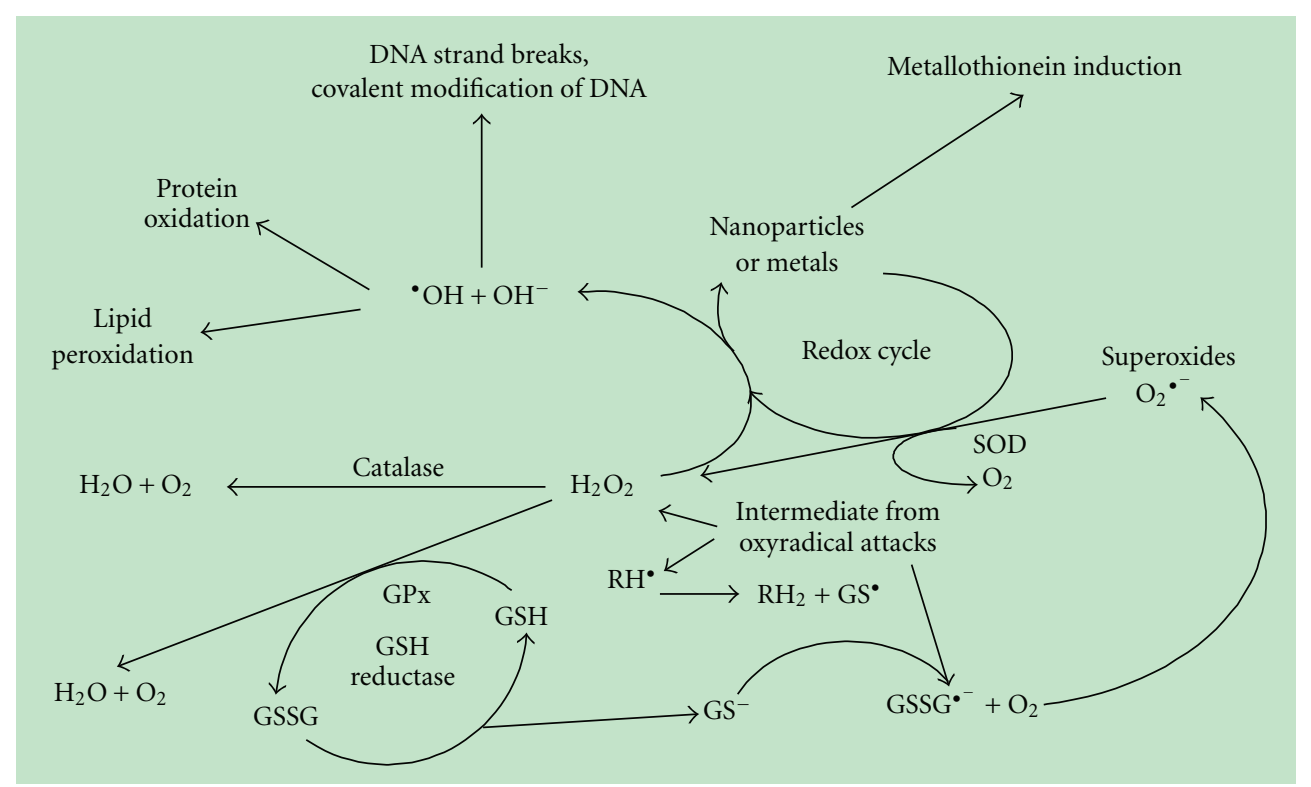

FIgURE 2: Interaction and the adverse effects of nanoparticles on biological systems.

to angiogenic tumor tissues and a similar accumulation of nanoparticles in angiogenic tissues of embryos is observed. Recently, trophic transfer of nanoparticles between aquatic invertebrates was demonstrated and it was found that the nanoparticles can be ingested and transferred between species [71]. Several studies have been carried out in semiconductor nanocrystals (i.e., quantum dots) in the blood stream of rodents. Larson et al. demonstrated that quantum dots could be used to image vasculature (using two-photon excitation) in dermis of mice [72]. Semiconductor quantum dots are nanoparticles with intense, stable fluorescence and could enable the detection of tens to hundreds of cancer biomarkers in blood assays, on cancer tissue biopsies, or as contrast agents for medical imaging. Smith and coworkers [73] have developed some functionalized quantum dots for tumor targeting in mice however and no study has been made to measure directly the concentration of the quantum dots in the blood or whether or not they were aggregated and hence the toxicity level of these quantum dots has not been checked.

3.1. Toxicity of Silver Nanoparticles to Mammalian Cells. Recently numerous in vitro studies have shown that $\mathrm{Ag}$ nanoparticles have potential to induce toxicity in cells derived from a variety of organs. The use of Ag nanoparticles in cosmetics and textiles has substantially increased the potential for human skin exposure. Recently, a study was carried out by using an artificial human skin exposure, which demonstrated that silver could be released from antibacterial fabric products into sweat [74]. It was demonstrated that silver release was dependent on the quantity of silver coating, fabric quality, $\mathrm{pH}$, and sweat formulation. On exposing keratinocytes with extracts of some wound dressings containing silver, it was observed that extracts containing Ag nanoparticles were among the most cytotoxic [75]. It has also been reported that nanocrystalline silver dressing (acticoat) is cytotoxic to cultured keratinocytes and should not be applied as a topical dressing on cultured skin grafts [76]. Ag nanoparticle crystals released from a commercial dressing were found to be toxic to both keratinocytes and fibroblasts [77]. It is interesting to see that fibroblasts appeared to be more sensitive to Ag nanoparticles than keratinocytes. Ag nanoparticles are found to induce cell death and oxidative stress in human fibrosarcoma and skin carcinoma cells [78] and it was demonstrated that Ag nanoparticles could enter cells and cause DNA damage and apoptosis in fibroblasts and liver cells [79]. The possible mechanism of silver nanoparticle toxicity in fibroblasts has been elaborated [80] and Ag nanoparticles have been found to induce reactive oxygen species (ROS) and release of cytochrome c into the cytosol and translocation of Bax protein to mitochondria. These observations indicate that Ag nanoparticle-mediated apoptosis was mitochondria-dependent in fibroblasts. Further observations have suggested that Ag nanoparticles induce a p53-mediated apoptotic pathway through which most of the chemotherapeutic drugs trigger apoptosis [81]. It has been demonstrated by different studies that the lungs and liver are major target tissues for prolonged Ag nanoparticles exposure [82, 83]. The studies of Ag nanoparticles on rat liver cells have show that significant depletion of the antioxidant glutathione reduced mitochondrial membrane potential and increased ROS [84]. These findings suggested that Ag nanoparticles cytotoxicity is likely mediated through oxidative stress in liver cells. The non-cytotoxic dose of Ag nanoparticles induced the expression of genes associated with cell cycle progression and apoptosis in human hepatoma cells [85]. By non-cytotoxic doses of Ag nanoparticles, toxicity in human mesenchymal stem cells was also caused [86]. It is clear by these two studies that Ag nanoparticles are unsafe even at non-cytotoxic doses. Studies on inhalation 
exposure have suggested that the lung is the easy target for nanoparticles and that inhaled particles may reach the brain through nasopharyngeal system [87]. However, there is limited information on in vitro toxicity of Ag nanoparticles in lung cells. Ag nanoparticles are found to reduce the cell viability of alveolar macrophages and lung epithelial cells [88]. Studies on oxidative stress-mediated size-dependent toxicity of Ag nanoparticles in alveolar macrophages have also been carried out [89]. Ag nanoparticles are also able to access human reproductive system through a variety of commercial products such as contraceptive devices and feminine hygiene products. Studies have shown that Ag nanoparticles cause toxicity to germ line stem cells through reduction in mitochondrial function and induction of membrane leakage and apoptosis [90]. The damage response of DNA to polysaccharide surface-functionalized (coated) and nonfunctionalized (uncoated) Ag nanoparticles in two marine mammalian cells, embryonic stem cells, and embryonic fibroblasts was examined [91] and it was found that both types of Ag nanoparticles stimulated apoptosis via upregulation of cell cycle checkpoint protein $\mathrm{p} 53$, DNA damage repair proteins Rad51, and phosphorylated-H2AX expression. These results suggested that the surface chemistry of Ag nanoparticles induce different DNA damage responses; that is, coated Ag nanoparticles induced more severe damage versus uncoated Ag nanoparticles. Polysaccharide-coated nanoparticles are more individually distributed while as agglomeration of the uncoated particles limits the surface area availability and access to membrane bound organelles. Other studies also reported that Ag nanoparticles coated with starch, bovine serum albumin (BSA), or polyvinyl pyrolidine (PVP) were toxic to cells and animals [92-94]. In some studies, uncoated silver nanoparticles have been reported to cause significant toxicity to human cells while carbon-coated particles did not cause any significant toxicity [95]. These studies suggested that toxicity of Ag nanoparticles was reduced due to the coating, which inhibited direct contact of particle surface with cellular components. The anti-angiogenic potential of Ag nanoparticles in bovine retinal endothelial cells (BRECs) was investigated and Ag nanoparticles blocked the proliferation and migration of BREC [96]. The effect of PVP-coated Ag nanoparticles and $\mathrm{Ag}^{+}$ions are compared on a human acute monocytic leukemia cell line (THP-1) and was found that both Ag nanoparticles and $\mathrm{Ag}^{+}$ions induced apoptosis through free oxygen radical generation [93]. Experiments using different nanoparticles have suggested that inhaled nanoparticles are very likely to deposit in the olfactory mucosa of the nasopharyngeal region and subsequently be translocated into the brain via the olfactory nerve [97]. Some studies reported that Ag nanoparticles caused cytotoxicity and dopamine depletion in neuroendocrine cells [98]. These preliminary findings clearly indicate that further research is required to assess the impact of Ag nanoparticles on brain cells.

3.2. Toxicity of Silver Nanoparticles on Nonmammalian Models. A number of nonmammalian animal models have been used to characterize adverse human and environmental health effects due to Ag nanoparticles exposure. Zebrafish (Danio rerio) is a well-established animal model to assess human health risk. In a recent review, Fako and Furgeson [99] suggested that zebrafish could be a correlative and predictive model to assess the toxic effects of nanomaterials. The use of zebrafish in biotoxicity screens is largely based on its close homology with the human genome. These genetic parallels impart physiological and anatomical similarities including the blood-brain barrier, endothelial cell biology, and immunogenic responses. Real-time study of the transport and biocompatibility of Ag nanoparticles at single nanoparticle resolution can provide additional knowledge about the delivery and effects of nanoparticles in vivo and generate new insights into molecular transport mechanisms during early embryonic development. Lee et al. [100] characterized the transport of a single Ag nanoparticle into zebrafish embryos and investigated their effects on early embryonic development. To accomplish this in vivo task, highly purified stable Ag nanoparticles were designed and single Ag nanoparticles optics were developed. These authors found that a single Ag nanoparticle was transported in and out of embryos through chorion-pore canals (CPC). Individual Ag nanoparticles were observed inside embryos at each developmental stage. Toxicity and types of abnormalities were highly dose dependent. Unlike other chemicals, a single nanoparticle can be directly imaged inside developing embryos at nanometer spatial resolution, thus offering new opportunities to unravel mechanisms of toxicity [100]. Asharani et al. [92] reported a concentration-dependent increase in mortality and hatching delay in Ag nanoparticles treated zebrafish embryos. Additionally, Ag nanoparticles resulted in concentration-dependent toxicity in phenotype, that is, abnormal body axes, twisted notochord, slow blood flow, pericardial edema, and cardiac arrhythmia. Bar-Ilan et al. [101] also reported size-dependent mortality and malformations in zebrafish embryos exposed to Ag nanoparticles. Choi et al. [102] studied liver toxicity of Ag nanoparticles in adult zebrafish. A number of cellular alterations including disruption of hepatic cell cords and apoptotic changes were observed. mRNA levels of free oxygen radical scavenging enzymes catalase and glutathione peroxidase 1a were reduced. Ag nanoparticles induced DNA damage, as demonstrated by the double-strand break marker $\gamma$-H2AX and the expression of $\mathrm{p} 53$ protein. In addition, the p53-related proapoptotic genes Bax, Noxa, and p21 were upregulated. Wu et al. [103] used early life stage Japanese medaka (Oryzias latipes) to investigate developmental toxicity of Ag nanoparticles. Retarded development and reduced pigmentation were observed in treated embryos. Maximum width of the optic tectum, an indicator of midbrain development, was reduced significantly in a dose-dependent manner. A variety of morphological malformations such as edema, spinal abnormalities, fin fold abnormalities, heart malformations, and eye defects were also observed. Subsequent studies by Chae et al. [104] found that Ag nanoparticles exposure induced DNA damage and induction of genes related to oxidative stress and metal detoxification/metabolism in the same experimental model. Further work using cell lines derived from Japanese medaka showed that Ag nanoparticles induced chromosomal aberrations, aneuploidy, and apoptosis [105]. Fish gills are in direct contact with the ambient water, making them 
vulnerable to water-suspended Ag nanoparticles. Bilberg et al. [106] studied the effect of Ag nanoparticles on oxygen consumption in Eurasian perch fish (Perca fluviatilis) and found that Ag NP impaired the tolerance to hypoxia. Scown et al. [107] showed that Ag nanoparticles uptake by the gills of rainbow trout fish (Oncorhynchus mykiss) induced the expression of oxidative stress-related genes. Laban et al. [108] found a concentration-dependent increase in larval abnormalities in fathead minnow (Pimephales promelas) in response to $\mathrm{Ag}$ nanoparticles exposure. These authors reported that both dissolved $\mathrm{Ag}^{+}$ions and particulate forms of silver contributed to embryonic toxicity. Filter-feeding bivalve mollusks such as oysters are valuable model species for characterizing nanoparticle bioavailability and interaction with basic cellular processes. Because adults release their gametes, their embryos and larvae are likely targets of environmental nanoparticle contamination. Ringwood et al. [109] characterized the toxicity of metal nanoparticles including Ag nanoparticles on embryonic development of oysters (Crassostrea virginica) and compared the relative sensitivity of embryos to adults. Results showed that $\mathrm{Ag}$ nanoparticles impaired normal embryonic development of oysters. Increased metallothionein (MT) mRNA levels were observed in both embryos and adult oysters. Ahmed et al. used the fruit fly (Drosophila melaogaster) as a model organism to evaluate the toxic potential of Ag nanoparticles [110]. Drosophila was chosen because of its well-documented genetics and developmental biology. This model raises fewer ethical objections and falls within the recommendations of the European Centre for the Validation of Alternative Methods (ECVAMs) [111]. It also allows for the evaluation of long-term effects in a short-time period due to its rapid reproduction and development. The model has been used for elucidating human disease [112] and in toxicologic studies $[113,114]$. The authors found that Ag nanoparticles induced heat shock protein 70 (Hsp 70), oxidative stress, DNA damage, and apoptosis in the third instar larvae [110]. These findings appear to suggest that Ag nanoparticles induced cell death via lipid peroxidation and oxidative stress. In a similar study, we also found that $\mathrm{Ag}$ nanoparticles upregulated Hsp 70 in adults following inhalation exposure [115]. Because of its high sensitivity, Hsp70 is suitable as an early indicator of cellular damage [116]. Caenorhabditis elegans are a model organism for elucidating cellular and molecular processes. Ag nanoparticles toxicity in C. elegans was investigated by Roh et al. [117] using functional toxicogenomics. Ag nanoparticles exerted considerable toxicity as demonstrated by decreased reproductive potential. Increased expressions of superoxide dismutases-3 (sod-3) and abnormal dauer formation protein (daf-12) genes were concurrently noted. The studies indicate that Ag nanoparticles produced reproductive failure, developmental malformations, and morphological deformities in a number of nonmammalian animal models. Common causes of Ag NP-induced toxicity included oxidative stress, DNA damage, and apoptosis.

3.3. Toxicity of Carbon Nanotubes. Currently, a number of toxicity tests have been carried out to check the toxicity of carbon nanotubes (CNTs). To date, the number of studies suggesting CNTs to be nontoxic in vivo outnumbers those proposing otherwise. For example, doses of $20 \mu \mathrm{g}$ diethylene triamine pentaacetic acid-(DTPA-) MWCNT/ $\mu \mathrm{L}$ phosphate buffer saline (PBS) and $20 \mu \mathrm{g}$ DTPA-SWCNT/ $\mu \mathrm{L}$ PBS were administered in different mice intravenously with no acute toxicity observed [118]. Yet another example, an intravenous injection of $\mathrm{a} \approx 20 \mu \mathrm{g}$ SWCNT/kg body weight concentration into specimens, confirmed safety of this dosage after a 24-hour period [119]. Laboratories around the world are tackling salient issues involving CNTs such as chronic toxicity and organ localization. As new research continues to support a positive outlook, other promising routes may be found through a careful look at data. A recent update has expanded the understanding of chronic toxicity of CNTs by asserting negligible toxicity in a sample of mice after 4 months of treatment [120]. New insight arises from the observation that the changes in neutrophil count for mice treated with PEGylated-oxidized SWCNTs were larger from counts from those mice treated with PEGylated SWCNT, which suggests that varying functionalization can modify toxicity. A recent in vivo cancer therapy study using CNTs originally designed as drug delivery enhancers was able to demonstrate that tumor cells respond to toxicity differently than do wildtype cells [121]. A marked decrease in breast cancer tumors in mice has been reported to occur by using SWCNTs conjugated with paclitaxel (a common chemotherapy drug), than by using paclitaxel alone. However, the data also shows that under some conditions, a few tumor-bearing mice treated with nonfunctionalized SWCNTs had a similar rate of tumor growth as that of the untreated control. This study then suggests that cancer cells may have a resistance mechanism against CNTs. If this was indeed correct, effective chemotherapy dosages, using CNTs, may have to be higher than what is currently known to be safe in order to be useful in drug delivery. Huczko and Lange found no effect of intratracheal instillation of CNTs on pulmonary functions of guinea pigs [122]. Lam et al. tested a variety of SWCNT samples with varying amounts of metal impurities and concluded that all SWCNT preparations induced dosedependent lung granulomas in mice [123]. Warheit et al. reported a mild and transient pulmonary inflammatory response in rats instilled intratracheally with SWCNTs, with subsequent development of multifocal granulomas in the lungs after 1 month in a mouse instillation study using highly purified SWCNTs [124]. Shvedova et al. found granulomas, lung fibrosis and a significant elevation in markers of toxicity in bronchoalveolar lavage (BAL) fluid and concluded that SWCNTs exerted greater toxicity on a mass basis than crystalline silica [125]. In contrast, no adverse effects were observed in rabbits injected intravenously with low levels of surfactant dispersed SWCNTs [126] and no significant toxic effects were seen following incubation of SWCNTs with cultured A549 human lung epithelial cells $[127,128]$.

3.4. Toxicity of Silica $\left(\mathrm{SiO}_{2}\right)$ Nanoparticles. Silica nanoparticles have been extensively studied and shown to be more useful in biological applications due to their low cytotoxic 
potential. For example, silica nanoparticles have been shown to have a low toxicity when administered in moderate doses [129-131]. Unfortunately, silica nanoparticles also tend to agglomerate and have been demonstrated to lead to protein aggregation in vitro at a dose of $25 \mu \mathrm{g} / \mathrm{mL}$ [132]. Oxidative stress has been implicated as an explanation behind silica nanoparticles cytotoxicity both in vitro and in vivo [133-135]. All these studies have reported cytotoxicity and oxidative stress, as determined by increasing lipid peroxidation (LPO), reactive oxygen species (ROS), and decreasing cellular glutathione (GSH level), but no similarity exists regarding dose response. When human lung epithelial cells (A549) were treated with $15 \mathrm{~nm}$ and $46 \mathrm{~nm}$ of amorphous silica nanoparticles at $50 \mathrm{ppm}(50 \mu \mathrm{g} / \mathrm{mL})$ for 48 hours, the cell viability decreased significantly but was same for both sizes and found to be $76.0 \%$ of control [136]. Similarly, Lison et al. have reported an $\mathrm{EC}_{50}$ of amorphous silica nanoparticles $(29.3 \pm 4.4 \mathrm{~nm})$ on A549 cells to be $50 \mu \mathrm{g} / \mathrm{mL}$ and an $\mathrm{EC}_{50}$ of $150 \mu \mathrm{g} / \mathrm{mL}$ on human endothelial (EAHY926) cells by MTT for $24 \mathrm{~h}$ [137]. When murine macrophages (RAW 264.7) were treated with silica nanoparticles for $24 \mathrm{~h}$ with impurities of $\mathrm{Al}_{2} \mathrm{O}_{3}, \mathrm{Fe}_{2} \mathrm{O}_{3}$, and $\mathrm{TiO}_{2}$ less than $0.05 \%$, $0.003 \%$, and $0.03 \%$, respectively, at $40 \mathrm{ppm}(40 \mu \mathrm{g} / \mathrm{mL})$, cell viability decreased to approximately $50 \%$ of control group and 50\% cell viability in human embryonic kidney cells (HEK293) was obtained for 24-hours exposure at $80.2 \pm 6.4 \mu \mathrm{g} / \mathrm{mL}$ for $20 \mathrm{~nm}$ and $140.3 \pm 8.6 \mu \mathrm{g} / \mathrm{mL}$ for $50 \mathrm{~nm}$ silica nanoparticles, respectively, with no information about other contaminants; however, a significant difference in cytotoxicity was observed for the two sizes $20 \mathrm{~nm}$ and $50 \mathrm{~nm}$ [138].

3.5. Toxicity of Copper Nanoparticles. Despite an increasing application of copper nanoparticles, there is a serious lack of information concerning their impact on human health and the environment. Copper is an essential trace element capable of producing toxic effects in animals or humans when ingested acutely or chronically, in excess [139]. There are numerous data regarding the toxicity of copper compounds. The sensitive targets of copper toxicity, after oral exposure, include the gastrointestinal system, liver, and kidneys. The manifestation of $\mathrm{Cu}$ poisoning mainly includes drowsiness and anorexia in the early stages [140, 141] as well as disruption of the epithelial lining of the gastrointestinal tract, hepatocellular necrosis, and acute tubular necrosis in the kidney [142]. Copper nanoparticles have shown great promise as osteoporosis-treatment drugs, antibacterial materials, additives in livestock and poultry feed, and intrauterine contraceptive devices. Furthermore, copper nanoparticles have been widely used in industry, for example, as an additive in lubricants for metallic coating and as a highly reactive catalyst in organic hydrogen reactions [143-145]. Usually, a variation in the size of metal nanoparticles results in bare nanoparticles possessing excessive surface energy, and this leads to an alteration in their catalytic properties [146]. This means that the dissolution of metal nanoparticles would occur once conditions are appropriate. Hence, for toxicology research in metal nanoparticles, it is essential to distinguish between the effects of nanoparticulates from dissolved metals. A recent report demonstrated that when mice were acutely exposed to nanocopper or microcopper particles, only nanocopper particles induced severe impairment in the kidney, liver, and spleen in mice [147]. Further study revealed that the toxicity of nanosized copper particles was highly correlated with the particle size/specific surface area. Compared to microcopper $(17 \mu \mathrm{m})$, nanocopper $(23.5 \mu \mathrm{m})$ can rapidly interact with artificial gastric acid juice and be transformed into ionic copper with ultrahigh reactivity. Moreover, metabolic alkalosis and copper accumulation in the kidneys were detected in mice that were orally exposed to nanocopper particles [148]. Although the potential risks of nanocopper particles on human health have been identified, subacute toxicity of it has not been described [149].

3.6. Toxicity of Fullerenes. Since the discovery of fullerene $\left(\mathrm{C}_{60}\right)$, this allotrope of carbon material has received considerable attention in the fields of electronics, superconductors, cosmetics, and medical agents [150]. Thus, future applications are expected to expand, although its environmental impact remains largely unknown. From a toxicological perspective, the exposure of water systems to $\mathrm{C}_{60}$ has been limited due to its hydrophobic and neutral surface; its water solubility is $1.3 \times 10^{11} \mu \mathrm{g} / \mathrm{mL}$ [151]. However, there has been a corresponding increase in the concerns about the fate of $\mathrm{C}_{60}$ in water phase and its subsequent risks to aquatic organisms following the discovery of the water-suspended fullerene aggregate $\left(\mathrm{nC}_{60}\right)[152,153]$. For instance, once $\mathrm{C}_{60}$ is released in natural water systems, the potential formation of $\mathrm{nC}_{60}$ may damage bacteria [153, 154], daphnids [155], fish [156], and even human health [157]. Recently Kim et al. have carried out an investigation into the toxicity of Fullerenes and developmental changes using Japanese medaka embryos in their study [158]. The authors report that the physicochemical properties of fullerene water suspensions $\left(\mathrm{nC}_{60}\right)$ and their subsequent toxicity were influenced by different preparation methods. The $\mathrm{nC}_{60}$ suspensions have been produced by three methods: toluene exchange $\left(\mathrm{Tol} / \mathrm{nC}_{60}\right)$, DMSO dissolving $\left(\mathrm{DMSO} / \mathrm{nC}_{60}\right)$, and stirring overtime $\left(\mathrm{Aqu} / \mathrm{nC}_{60}\right)$. The particle size, zeta potential, and $\mathrm{nC}_{60}$ structure have been found to be strongly dependent on both the type of aggregates formed and the test medium addition. Specifically, Tol/ $\mathrm{nC}_{60}$ exhibited small and spherical closed aggregates, whereas $\mathrm{DMSO} / \mathrm{nC}_{60}$ and $\mathrm{Aqu} / \mathrm{nC}_{60}$ presented mesoscale aggregates of smaller spherical aggregates. The embryonic toxicity and oxidative stress of Japanese medaka (Oryzias latipes) were determined by these differences in the physicochemical properties of $\mathrm{nC}_{60}$. The mortality and glutathione (GSH) induction of embryos were ranked in the order of $\mathrm{Tol} / \mathrm{nC}_{60}>$ $\mathrm{DMSO} / \mathrm{nC}_{60}>\mathrm{Aqu} / \mathrm{nC}_{60}$, and the morphological malformations were in the order of $\mathrm{DMSO} / \mathrm{nC}_{60}>\mathrm{Tol} / \mathrm{nC}_{60}>$ $\mathrm{Aqu} / \mathrm{nC}_{60}$. The mortality of $\mathrm{Tol} / \mathrm{nC}_{60}$ was attributed to its closely packed fullerene structure, which remained as largely underivatized $\mathrm{C}_{60}$. The malformations of $\mathrm{DMSO}_{\mathrm{n}} \mathrm{nC}_{60}$ might have originated from the coeffect of organic solvent remaining in the fullerene colloid [158]. 


\section{Methods to Access the Nanoparticle Toxicity}

4.1. Traditional Methods. To evaluate current available methodologies for toxicity screening of nanomaterials, several questions have to be answered.

(a) Are there any specific toxicological endpoints that are of higher concern for nanomaterials, such as neurological, cardiovascular, respiratory, endocrine disrupting, or immunological effects?

(b) Are current testing methods (organisms, exposure regimes, media, analytical methods, and test schemes) applicable to testing nanomaterials in standardized agency toxicity tests?

(c) Are current analytical methods capable of analyzing and quantifying intentionally produced nanomaterials to generate dose-response relationships?

Although there is no standard protocol for nanotoxicity testing currently, it will suffice to mention that the three key elements of a toxicity screening strategy should include physicochemical characterization of nanoparticles, in vitro assays (cellular and noncellular), and in vivo studies. It is important that the design be pragmatic and mechanismbased.

4.1.1. Physicochemical Characterization. Biological activity depends on physicochemical characteristics that are not usually considered in toxicity screening studies a strong likelihood. The major physicochemical characters include (1) size including surface area, size distribution, chemical composition (purity crystallinity, electronic properties, etc.); (2) solubility; (3) shape and aggregation; and (4) surface structure including surface reactivity, surface groups, and coating.

4.1.2. In Vitro Assays. Cellular assays should be reflected to portal-of-entry toxicity in lung, skin, and mucus membranes as well as noxious effects on target tissue. Protein interactions should be also included in in vitro assays. For medicinal application, the nanomaterials often carry diagnostic reagents and/or drugs. The surface properties of nanomaterials are often modified with biomolecules. How to identify the specifictoxicity induced by nanoparticles from the effects of the drugs, or biomolecules is a challenge. Potential harmful effects will be induced when these nanomaterials are used in some medical situation, such as X-ray, UV or ultrasonic. The methods to evaluate these combinative effects should be developed.

4.1.3. In Vivo Studies. This is used to study portal-of-entry and target organ injury with disease specific animal model. The pharmacokinetic and dynamic studies should be also included.

4.1.4. Systemic Responses. It is important to assess systemic responses, such as oxidative stress, cytotoxicity, immuneinflammatory response, neurotoxicity, carcinogenesis, and endocrine disruptions. In particular, the physicochemical properties of nanomaterials are characterized and they are tested for their basal cytotoxicity, carcinogenic potential, genotoxicity, chronic toxicity, development toxicity, reproductive, and immunotoxicity using the corresponding in vitro systems.

4.2. Novel Methods. There are a number of reviews on nanoparticle toxicity, including interaction(s) with biological materials $[159,160]$. The toxicity of nanomaterials has been mostly studied on cultured cell lines and some excellent reviews detail the effect of nanoparticle concentration on the morphology and metabolism of the cells when exposed to nanoparticles [21]. Briefly, at low doses $\left(<10 \mu \mathrm{g} \mathrm{mL}^{-1}\right)$, most nanoparticles appear to have low to minimal cytotoxicity irregardless of whether they are carbon-, metal-, or semiconductor-based, at least for acute exposure. For higher nanoparticle doses, almost all cell lines show some toxicity (usually scored as lower viability). The most compelling physicochemical nanoparticle attribute that can be related to cytotoxicity is surface charge, with toxicity increasing in the following way neutral $<$ anionic $<$ cationic $[21,160]$. It is hypothesized that the cationic nanoparticles interact more strongly with cell membranes, which tend to be negatively charged. Once internalized into cells, a common mechanism is that certain nanoparticles generate reactive oxygen species (ROS), which damage the cellular machinery. However, this is not true for all nanoparticles and further mechanistic studies are needed. Moreover, there is a general call for more in vivo (i.e., whole organism) studies to examine hazard (i.e., toxicity) and exposure (i.e., routes of bioaccumulation) that go beyond the typical cytotoxicity studies alluded to above. There is a growing consensus that important physical properties of nanoparticles are related to their potential Environmental health and Safety (EHS) risk [9, 161]. The properties are size, shape, surface charge density, surface chemistry, and degree of aggregation [55-57]. A predictive model for estimating the toxicity of nanoparticles can only be developed when the effect of these physical properties on bioaccumulation and cytotoxicity of nanoparticles is understood. It is therefore critical to develop methods to analyze these properties of nanoparticles both in vitro and in vivo, since their biological environments might affect nanoparticle properties.

Currently, systemic biological approaches (genomics, proteomics, and metabonomics/metabolomics) have been widely applied in the toxicology research field and have provided valuable information in this regard [162, 163]. Among them, metabolomics is a rapidly developing new discipline which is the collection of the global metabolic data and their interpretation (both spectral and biochemical) using modern spectroscopic techniques and appropriate statistical approaches [163]. It may provide us with better, more useful information with higher throughput at a lower cost than genomics, transcriptomics, or proteomics. Thus far, a variety of spectroscopic techniques have been used to generate metabolomic data sets, such as nuclear magnetic resonance (NMR) spectroscopy, liquid chromatographycoupled mass spectrometry (LC-MS), tandem and Fourier 
transform mass spectrometry, capillary electrophoresis, and infrared spectroscopy $[164,165]$. In contrast with other means, ${ }^{1}$ HNMR has two significant advantages. One is the minimal sample preparation required and the second is its nonselectivity in metabolite detection and ability of multiple metabolite quantification. ${ }^{1} \mathrm{HNMR}$ provides both quantitative and structural information by enabling to detect soluble proton-containing small-molecular-weight metabolites less than $1000 \mathrm{Da}$ that are present in concentrations above $10 \mu \mathrm{M}$. Given the amount and complexity of spectroscopic data from NMR studies, pattern recognition approaches and chemometric analysis were usually used to implement the interpretation of spectral data [166, 167]. Principal component analysis (PCA) is one such routinely used pattern recognition method where the NMR spectra are reduced to a set of peak intensity descriptors and analyzed to identify similarities and differences in biochemical characteristics between control and treated animals. Compared to the traditional techniques, the prominent advantages of NMR-based metabolomic approach include timesaving, sensitive, non- or less invasive, and holistic view of the biochemical variations. So, it has been widely used in the toxicity evaluations of candidate drugs [168, 169]. Recent studies also showed that integrated metabolomic approach is useful in mechanistic toxicological studies [170].

4.3. Bioluminescence-Based Nanotoxicity Test. Luminous bacteria are well-known species that emit bright bioluminescence. The bioluminescence intensity is directly proportional to the matebolic activity of the bacterial population. Any inhibition of enzymatic activity can cause a decrease in the bioluminescence [171]. By using this unique property, it provides a simple way to measure the toxicity of different compounds based on their bioluminescence inhibition [172, 173]. Zheng et al. have used luminous bacteria as a microbial sensing agent to measure the toxicity of gold nanoparticles and carbon nanotubes [174]. The bacteria-based toxicity test took only 15 minutes for the whole assay and gave promising results comparable to other standard methods.

\section{Conclusion}

With growing public awareness about the potential negative effects of scientific techniques, new technologies are today viewed with more skepticism than before. Therefore, researchers and engineers aiming to introduce new pieces of technology must be much surer of the benignity of their contribution. The central question is whether the unknown risks of engineered nanoparticles in particular their environmental impact are outweighing their established benefits for society. Although engineered nanomaterials may create toxic effects, there are currently no conclusive data to establish that the present levels of nanomaterials are likely or unlikely to pose any danger to public health. At the same time, one can no longer postpone safety evaluations of nanomaterials and there is a pressing need to check the toxicity of nanomaterials. Active measures need to be taken to and are in fact critical for ensuring a sustainable nanotechnology industry.

\section{References}

[1] Z. Liu, F. Kiessling, and J. Gatjens, "Advanced nanomaterials in multimodal imaging: design, functionalization, and biomedical applications," Journal of Nanomaterials, vol. 2010, pp. 1-15, 2010.

[2] H. Zeng and S. Sun, "Syntheses, properties, and potential applications of multicomponent magnetic nanoparticles," Advanced Functional Materials, vol. 18, no. 3, pp. 391-400, 2008.

[3] V. L. Colvin, "The potential environmental impact of engineered nanomaterials," Nature Biotechnology, vol. 21, no. 10, pp. 1166-1170, 2003.

[4] T. Matsunaga, H. Togo, T. Kikuchi, and T. Tanaka, "Production of luciferase-magnetic particle complex by recombinant Magnetospirillum sp. AMB-1," Biotechnology and Bioengineering, vol. 70, no. 6, pp. 704-709, 2000.

[5] T. Matsunaga and T. Sakaguchi, "Molecular mechanism of magnet formation in bacteria," Journal of Bioscience and Bioengineering, vol. 90, no. 1, pp. 1-13, 2000.

[6] G. Oberdörster, E. Oberdörster, and J. Oberdörster, "Nanotoxicology: an emerging discipline evolving from studies of ultrafine particles," Environmental Health Perspectives, vol. 113, no. 7, pp. 823-839, 2005.

[7] B. Arvidson, "A review of axonal transport of metals," Toxicology, vol. 88, no. 1-3, pp. 1-14, 1994.

[8] S. E. Cross, B. Innes, M. S. Roberts, T. Tsuzuki, T. A. Robertson, and P. McCormick, "Human skin penetration of sunscreen nanoparticles: in-vitro assessment of a novel micronized zinc oxide formulation," Skin Pharmacology and Physiology, vol. 20, no. 3, pp. 148-154, 2007.

[9] B. Nowack and T. D. Bucheli, "Occurrence, behavior and effects of nanoparticles in the environment," Environmental Pollution, vol. 150, no. 1, pp. 5-22, 2007.

[10] P. H. Hoet, I. Brüske-Hohlfeld, and O. V. Salata, "Nanoparticles_known and unknown health risks," Journal of Nanobiotechnology, vol. 2, article 12, 2004.

[11] R. Duffin, N. L. Mills, and K. Donaldson, "Nanoparticles-a thoracic toxicology perspective," Yonsei Medical Journal, vol. 48, no. 4, pp. 561-572, 2007.

[12] R. J. Aitken, K. S. Creely, and C. L. Tran, "Nanoparticles: an occupational hygiene review," Institute of Occupational Medicine for the Health and Safety Executive, pp. 1-113, 2004.

[13] H. J. Johnston, G. Hutchison, F. M. Christensen, S. Peters, S. Hankin, and V. Stone, "A review of the in vivo and in vitro toxicity of silver and gold particulates: particle attributes and biological mechanisms responsible for the observed toxicity," Critical Reviews in Toxicology, vol. 40, no. 4, pp. 328-346, 2010.

[14] J. S. Brown, K. L. Zeman, and W. D. Bennett, "Ultrafine particle deposition and clearance in the healthy and obstructed lung," American Journal of Respiratory and Critical Care Medicine, vol. 166, no. 9, pp. 1240-1247, 2002.

[15] B. J. Marquis, S. A. Love, K. L. Braun, and C. L. Haynes, "Analytical methods to assess nanoparticle toxicity," Analyst, vol. 134, no. 3, pp. 425-439, 2009.

[16] M. Kulmala, H. Vehkamäki, T. Petäjä et al., "Formation and growth rates of ultrafine atmospheric particles: a review of observations," Journal of Aerosol Science, vol. 35, no. 2, pp. 143-176, 2004. 
[17] M. P. Holsapple, W. H. Farland, T. D. Landry et al., "Research strategies for safety evaluation of nanomaterials, part II: toxicological and safety evaluation of nanomaterials, current challenges and data needs," Toxicological Sciences, vol. 88, no. 1, pp. 12-17, 2005.

[18] N. Li, C. Sioutas, A. Cho et al., "Ultrafine particulate pollutants induce oxidative stress and mitochondrial damage," Environmental Health Perspectives, vol. 111, no. 4, pp. 455460, 2003.

[19] M. Geiser, B. Rothen-Rutishauser, N. Kapp et al., "Ultrafine particles cross cellular membranes by nonphagocytic mechanisms in lungs and in cultured cells," Environmental Health Perspectives, vol. 113, no. 11, pp. 1555-1560, 2005.

[20] R. Savić, L. Luo, A. Eisenberg, and D. Maysinger, "Micellar nanocontainers distribute to defined cytoplasmic organelles," Science, vol. 300, no. 5619, pp. 615-618, 2003.

[21] A. Hoshino, K. Fujioka, T. Oku et al., "Quantum dots targeted to the assigned organelle in living cells," Microbiology and Immunology, vol. 48, no. 12, pp. 985-994, 2004.

[22] V. Salnikov, Y. O. Lukyánenko, C. A. Frederick, W. J. Lederer, and V. Lukyánenko, "Probing the outer mitochondrial membrane in cardiac mitochondria with nanoparticles," Biophysical Journal, vol. 92, no. 3, pp. 1058-1071, 2007.

[23] K. Donaldson and V. Stone, "Current hypotheses on the mechanisms of toxicity of ultrafine particles," Annali dell'Istituto Superiore di Sanita, vol. 39, no. 3, pp. 405-410, 2003.

[24] A. Hett, "Nanotechnology: small matter, many unknowns," Swiss Re publications, 2004.

[25] G. Oberdörster, A. Maynard, K. Donaldson et al., "Principles for characterizing the potential human health effects from exposure to nanomaterials: elements of a screening strategy," Particle and Fibre Toxicology, vol. 2, article 8, 2005.

[26] Z. Li, T. Hulderman, R. Salmen et al., "Cardiovascular effects of pulmonary exposure to single-wall carbon nanotubes," Environmental Health Perspectives, vol. 115, no. 3, pp. 377382, 2007.

[27] K. Donaldson, R. Aitken, L. Tran et al., "Carbon nanotubes: a review of their properties in relation to pulmonary toxicology and workplace safety," Toxicological Sciences, vol. 92, no. 1, pp. 5-22, 2006.

[28] K. E. Cha and H. Myung, "Cytotoxic effects of nanoparticles assessed in vitro and in vivo," Journal of Microbiology and Biotechnology, vol. 17, no. 9, pp. 1573-1578, 2007.

[29] A. Huczko, H. Lange, E. Calko, H. Grubek-Jaworska, and P. Droszcz, "Physiological testing of carbon nanotubes: are they asbestos-like?” Fullerene Science and Technology, vol. 9, no. 2, pp. 251-254, 2001.

[30] C. P. Firme and P. R. Bandaru, "Toxicity issues in the application of carbon nanotubes to biological systems," Nanomedicine: Nanotechnology, Biology, and Medicine, vol. 6, no. 2, pp. 245-256, 2010.

[31] P. J. A. Borm and W. Kreyling, "Toxicological hazards of inhaled nanoparticles-potential implications for drug delivery," Journal of Nanoscience and Nanotechnology, vol. 4, no. 5, pp. 521-531, 2004.

[32] A. A. Shvedova, E. R. Kisin, R. Mercer et al., "Unusual inflammatory and fibrogenic pulmonary responses to singlewalled carbon nanotubes in mice," American Journal of Physiology, vol. 289, no. 5, pp. L698-L708, 2005.

[33] D. C. Chalupa, P. E. Morrow, G. Oberdörster, M. J. Utell, and M. W. Frampton, "Ultrafine particle deposition in subjects with asthma," Environmental Health Perspectives, vol. 112, no. 8, pp. 879-882, 2004.
[34] R. D. Handy, T. B. Henry, T. M. Scown, B. D. Johnston, and C. R. Tyler, "Manufactured nanoparticles: their uptake and effects on fish-a mechanistic analysis," Ecotoxicology, vol. 17, no. 5, pp. 396-409, 2008.

[35] B. Nowack and T. D. Bucheli, "Occurrence, behavior and effects of nanoparticles in the environment," Environmental Pollution, vol. 150, no. 1, pp. 5-22, 2007.

[36] N. Lewinski, V. Colvin, and R. Drezek, "Cytotoxicity of nanopartides," Small, vol. 4, no. 1, pp. 26-49, 2008.

[37] R. F. Service, "Nanotechnology grows up," Science, vol. 304, no. 5678, pp. 1732-1734, 2004.

[38] G. Oberdörster, E. Oberdörster, and J. Oberdörster, "Nanotoxicology: an emerging discipline evolving from studies of ultrafine particles," Environmental Health Perspectives, vol. 113, no. 7, pp. 823-839, 2005.

[39] R. D. Handy, R. Owen, and E. Valsami-Jones, "The ecotoxicology of nanoparticles and nanomaterials: current status, knowledge gaps, challenges, and future needs," Ecotoxicology, vol. 17, no. 5, pp. 315-325, 2008.

[40] S. M. Hussain, K. L. Hess, J. M. Gearhart, K. T. Geiss, and J. J. Schlager, "In vitro toxicity of nanoparticles in BRL 3A rat liver cells," Toxicology in Vitro, vol. 19, no. 7, pp. 975-983, 2005.

[41] C. M. Sayes, J. D. Fortner, W. Guo et al., "The differential cytotoxicity of water-soluble fullerenes," Nano Letters, vol. 4, no. 10, pp. 1881-1887, 2004.

[42] G. L. Baker, A. Gupta, M. L. Clark et al., "Inhalation toxicity and lung toxicokinetics of $\mathrm{C}_{60}$ fullerene nanoparticles and microparticles," Toxicological Sciences, vol. 101, no. 1, pp. 122-131, 2008.

[43] A. C. P. Elder, R. Gelein, J. N. Finkelstein, C. Cox, and G. Oberdorster, "Pulmonary inflammatory response to inhaled ultrafine particles is modified by age, ozone exposure, and bacterial toxin," Inhalation Toxicology, vol. 12, no. 4, pp. 227246, 2000.

[44] E. Oberdörster, "Manufactured nanomaterials (fullerenes, $\mathrm{C}_{60}$ ) induce oxidative stress in the brain of juvenile largemouth bass," Environmental Health Perspectives, vol. 112, no. 10, pp. 1058-1062, 2004.

[45] S. B. Lovern and R. Klaper, "Daphnia magna mortality when exposed to titanium dioxide and fullerene $\left(\mathrm{C}_{60}\right)$ nanoparticles," Environmental Toxicology and Chemistry, vol. 25, no. 4, pp. 1132-1137, 2006.

[46] D. Y. Lyon, L. K. Adams, J. C. Falkner, and P. J. J. Alvarez, "Antibacterial activity of fullerene water suspensions: effects of preparation method and particle size," Environmental Science and Technology, vol. 40, no. 14, pp. 4360-4366, 2006.

[47] D. Y. Lyon, J. D. Fortner, C. M. Sayes, V. L. Colvin, and J. B. Hughes, "Bacterial cell association and antimicrobial activity of a $\mathrm{C}_{60}$ water suspension," Environmental Toxicology and Chemistry, vol. 24, no. 11, pp. 2757-2762, 2005.

[48] H. E. Wichmann, C. Spix, T. Tuch et al., "Daily mortality and fine and ultrafine particles in Erfurt, Germany part I: role of particle number and particle mass," Research Report, no. 98, pp. 5-87, 2000.

[49] A. M. Derfus, W. C. W. Chan, and S. N. Bhatia, "Probing the cytotoxicity of semiconductor quantum dots," Nano Letters, vol. 4, no. 1, pp. 11-18, 2004.

[50] D. B. Warheit, T. R. Webb, C. M. Sayes, V. L. Colvin, and K. L. Reed, "Pulmonary instillation studies with nanoscale $\mathrm{TiO}_{2}$ rods and dots in rats: toxicity is not dependent upon particle size and surface area," Toxicological Sciences, vol. 91, no. 1, pp. 227-236, 2006. 
[51] V. H. Grassian, P. T. O’Shaughnessy, A. Adamcakova-Dodd, J. M. Pettibone, and P. S. Thorne, "Inhalation exposure study of Titanium dioxide nanoparticles with a primary particle size of 2 to $5 \mathrm{~nm}$," Environmental Health Perspectives, vol. 115, no. 3, pp. 397-402, 2007.

[52] J. M. Pettibone, A. Adamcakova-Dodd, P. S. Thorne, P. T. O'Shaughnessy, J. A. Weydert, and V. H. Grassian, "Inflammatory response of mice following inhalation exposure to iron and copper nanoparticles," Nanotoxicology, vol. 2, no. 4, pp. 189-204, 2008.

[53] A. Nemmar, M. F. Hoylaerts, P. H. M. Hoet, J. Vermylen, and B. Nemery, "Size effect of intratracheally instilled particles on pulmonary inflammation and vascular thrombosis," Toxicology and Applied Pharmacology, vol. 186, no. 1, pp. 3845, 2003.

[54] B. Veronesi, C. D. Haar, L. Lee, and M. Oortgiesen, "The surface charge of visible particulate matter predicts biological activation in human bronchial epithelial cells," Toxicology and Applied Pharmacology, vol. 178, no. 3, pp. 144-154, 2002.

[55] D. B. Warheit, B. R. Laurence, K. L. Reed, D. H. Roach, G. A. M. Reynolds, and T. R. Webb, "Comparative pulmonary toxicity assessment of single-wall carbon nanotubes in rats," Toxicological Sciences, vol. 77, no. 1, pp. 117-125, 2004.

[56] G. Oberdörster, J. Ferin, and B. E. Lehnert, "Correlation between particle size, in vivo particle persistence, and lung injury," Environmental Health Perspectives, vol. 102, no. 5, pp. 173-179, 1994.

[57] M. Geiser, S. Schürch, and P. Gehr, "Influence of surface chemistry and topography of particles on their immersion into the lung's surface-lining layer," Journal of Applied Physiology, vol. 94, no. 5, pp. 1793-1801, 2003.

[58] D. M. Brown, K. Donaldson, P. J. Borm et al., "Calcium and ROS-mediated activation of transcription factors and TNF- $\alpha$ cytokine gene expression in macrophages exposed to ultrafine particles," American Journal of Physiology, vol. 286, no. 2, pp. L344-L353, 2004.

[59] C. S. Hansen, M. Sheykhzade, P. Møller et al., "Diesel exhaust particles induce endothelial dysfunction in $\mathrm{apoE}^{-/}$mice," Toxicology and Applied Pharmacology, vol. 219, no. 1, pp. 2432, 2007.

[60] Z. Li, T. Hulderman, R. Salmen et al., "Cardiovascular effects of pulmonary exposure to single-wall carbon nanotubes," Environmental Health Perspectives, vol. 115, no. 3, pp. 377382, 2007.

[61] P. P. Simeonova and A. Erdely, "Engineered nanoparticle respiratory exposure and potential risks for cardiovascular toxicity: predictive tests and biomarkers," Inhalation Toxicology, vol. 21, no. 1, pp. 68-73, 2009.

[62] P. R. Lockman, J. M. Koziara, R. J. Mumper, and D. Allen, "Nanoparticle surface charges alter blood-brain barrier integrity and permeability," Journal of Drug Targeting, vol. 12, no. 9-10, pp. 635-641, 2004.

[63] Y. Jallouli, A. Paillard, J. Chang, E. Sevin, and D. Betbeder, "Influence of surface charge and inner composition of porous nanoparticles to cross blood-brain barrier in vitro," International Journal of Pharmaceutics, vol. 344, no. 1-2, pp. 103-109, 2007.

[64] T. C. Long, N. Saleh, R. D. Tilton, G. V. Lowry, and B. Veronesi, "Titanium dioxide (P25) produces reactive oxygen species in immortalized brain microglia (BV2): implications for nanoparticle neurotoxicity," Environmental Science and Technology, vol. 40, no. 14, pp. 4346-4352, 2006.
[65] A. Peters, B. Veronesi, L. Calderón-Garcidueñas et al., "Translocation and potential neurological effects of fine and ultrafine particles a critical update," Particle and Fibre Toxicology, vol. 3, article 13, 2006.

[66] B. Baroli, M. G. Ennas, F. Loffredo, M. Isola, R. Pinna, and M. A. López-Quintela, "Penetration of metallic nanoparticles in human full-thickness skin," Journal of Investigative Dermatology, vol. 127, no. 7, pp. 1701-1712, 2007.

[67] A. V. Zvyagin, X. Zhao, A. Gierden, W. Sanchez, J. A. Ross, and M. S. Roberts, "Imaging of zinc oxide nanoparticle penetration in human skin in vitro and in vivo," Journal of Biomedical Optics, vol. 13, no. 6, Article ID 064031, 2008.

[68] A. Nel, T. Xia, L. Mädler, and N. Li, "Toxic potential of materials at the nanolevel," Science, vol. 311, no. 5761, pp. 622-627, 2006.

[69] G. G. Xiao, M. Wang, N. Li, J. A. Loo, and A. E. Nel, "Use of proteomics to demonstrate a hierarchical oxidative stress response to diesel exhaust particle chemicals in a macrophage cell line," Journal of Biological Chemistry, vol. 278, no. 50, pp. 50781-50790, 2003.

[70] A. A. Clancy, Y. Gregoriou, K. Yaehne, and D. T. Cramb, "Measuring properties of nanoparticles in embryonic blood vessels: towards a physicochemical basis for nanotoxicity," Chemical Physics Letters, vol. 488, no. 4-6, pp. 99-111, 2010.

[71] R. D. Holbrook, K. E. Murphy, J. B. Morrow, and K. D. Cole, "Trophic transfer of nanoparticles in a simplified invertebrate food web," Nature Nanotechnology, vol. 3, no. 6, pp. 352-355, 2008.

[72] D. R. Larson, W. R. Zipfel, R. M. Williams et al., "Watersoluble quantum dots for multiphoton fluorescence imaging in vivo," Science, vol. 300, no. 5624, pp. 1434-1436, 2003.

[73] A. M. Smith, S. Dave, S. Nie, L. True, and X. Gao, "Multicolor quantum dots for molecular diagnostics of cancer," Expert Review of Molecular Diagnostics, vol. 6, no. 2, pp. 231-244, 2006.

[74] K. Kulthong, S. Srisung, K. Boonpavanitchakul, W. Kangwansupamonkon, and R. Maniratanachote, "Determination of silver nanoparticle release from antibacterial fabrics into artificial sweat," Particle and Fibre Toxicology, vol. 7, article 8, 2010.

[75] J. E. Paddle-Ledinek, Z. Nasa, and H. J. Cleland, "Effect of different wound dressings on cell viability and proliferation," Plastic and Reconstructive Surgery, vol. 117, no. 7, 2006.

[76] P. K. Lam, E. S. Y. Chan, W. S. Ho, and C. T. Liew, "In vitro cytotoxicity testing of a nanocrystalline silver dressing (Acticoat) on cultured keratinocytes," British Journal of Biomedical Science, vol. 61, no. 3, pp. 125-127, 2004.

[77] V. K. M. Poon and A. Burd, "In vitro cytotoxity of silver: implication for clinical wound care," Burns, vol. 30, no. 2, pp. 140-147, 2004.

[78] S. Arora, J. Jain, J. M. Rajwade, and K. M. Paknikar, "Cellular responses induced by silver nanoparticles: in vitro studies," Toxicology Letters, vol. 179, no. 2, pp. 93-100, 2008.

[79] S. Arora, J. Jain, J. M. Rajwade, and K. M. Paknikar, "Interactions of silver nanoparticles with primary mouse fibroblasts and liver cells," Toxicology and Applied Pharmacology, vol. 236, no. 3, pp. 310-318, 2009.

[80] Y. H. Hsin, C. F. Chen, S. Huang, T. S. Shih, P. S. Lai, and P. J. Chueh, "The apoptotic effect of nanosilver is mediated by a ROS- and JNK-dependent mechanism involving the mitochondrial pathway in NIH3T3 cells," Toxicology Letters, vol. 179, no. 3, pp. 130-139, 2008. 
[81] P. Gopinath, S. K. Gogoi, P. Sanpui, A. Paul, A. Chattopadhyay, and S. S. Ghosh, "Signaling gene cascade in silver nanoparticle induced apoptosis," Colloids and Surfaces B, vol. 77, no. 2, pp. 240-245, 2010.

[82] S. Takenaka, E. Karg, C. Roth et al., "Pulmonary and systemic distribution of inhaled ultrafine silver particles in rats," Environmental Health Perspectives, vol. 109, no. 4, pp. 547$551,2001$.

[83] J. H. Sung, J. H. Ji, J. U. Yoon et al., "Lung function changes in Sprague-Dawley rats after prolonged inhalation exposure to silver nanoparticles," Inhalation Toxicology, vol. 20, no. 6, pp. 567-574, 2008.

[84] S. M. Hussain, K. L. Hess, J. M. Gearhart, K. T. Geiss, and J. J. Schlager, "In vitro toxicity of nanoparticles in BRL 3A rat liver cells," Toxicology in Vitro, vol. 19, no. 7, pp. 975-983, 2005.

[85] K. Kawata, M. Osawa, and S. Okabe, "In vitro toxicity of silver nanoparticles at noncytotoxic doses to HepG2 human hepatoma cells," Environmental Science and Technology, vol. 43, no. 15, pp. 6046-6051, 2009.

[86] C. Greulich, S. Kittler, M. Epple, G. Muhr, and M. Köller, "Studies on the biocompatibility and the interaction of silver nanoparticles with human mesenchymal stem cells (hMSCs)," Langenbeck's Archives of Surgery, vol. 394, no. 3, pp. 495-502, 2009.

[87] G. Oberdörster, Z. Sharp, V. Atudorei et al., "Translocation of inhaled ultrafine particles to the brain," Inhalation Toxicology, vol. 16, no. 6-7, pp. 437-445, 2004.

[88] K. Soto, K. M. Garza, and L. E. Murr, "Cytotoxic effects of aggregated nanomaterials," Acta Biomaterialia, vol. 3, no. 3, pp. 351-358, 2007.

[89] C. Carlson, S. M. Hussein, A. M. Schrand et al., "Unique cellular interaction of silver nanoparticles: size-dependent generation of reactive oxygen species," Journal of Physical Chemistry B, vol. 112, no. 43, pp. 13608-13619, 2008.

[90] L. Braydich-Stolle, S. Hussain, J. J. Schlager, and M. C. Hofmann, "In vitro cytotoxicity of nanoparticles in mammalian germline stem cells," Toxicological Sciences, vol. 88, no. 2, pp. 412-419, 2005.

[91] M. Ahamed, M. Karns, M. Goodson et al., "DNA damage response to different surface chemistry of silver nanoparticles in mammalian cells," Toxicology and Applied Pharmacology, vol. 233, no. 3, pp. 404-410, 2008.

[92] P. V. Asharani, Y. L. Wu, Z. Gong, and S. Valiyaveettil, "Toxicity of silver nanoparticles in zebrafish models," Nanotechnology, vol. 19, no. 25, Article ID 255102, 2008.

[93] R. Foldbjerg, P. Olesen, M. Hougaard, D. A. Dang, H. J. Hoffmann, and H. Autrup, "PVP-coated silver nanoparticles and silver ions induce reactive oxygen species, apoptosis and necrosis in THP-1 monocytes," Toxicology Letters, vol. 190, no. 2, pp. 156-162, 2009.

[94] F. F. Larese, F. D’Agostin, M. Crosera et al., "Human skin penetration of silver nanoparticles through intact and damaged skin," Toxicology, vol. 255, no. 1-2, pp. 33-37, 2009.

[95] M. E. Samberg, S. J. Oldenburg, and N. A. Monteiro-Riviere, "Evaluation of silver nanoparticle toxicity in skin in vivo and keratinocytes in vitro," Environmental Health Perspectives, vol. 118, no. 3, pp. 407-413, 2010.

[96] K. Kalishwaralal, E. Banumathi, S. R. K. Pandian et al., "Silver nanoparticles inhibit VEGF induced cell proliferation and migration in bovine retinal endothelial cells," Colloids and Surfaces B, vol. 73, no. 1, pp. 51-57, 2009.
[97] A. Elder, R. Gelein, V. Silva et al., "Translocation of inhaled ultrafine manganese oxide particles to the central nervous system," Environmental Health Perspectives, vol. 114, no. 8, pp. 1172-1178, 2006.

[98] S. M. Hussain, A. K. Javorina, A. M. Schrand, H. M. H. M. Duhart, S. F. Ali, and J. J. Schlager, "The interaction of manganese nanoparticles with PC-12 cells induces dopamine depletion," Toxicological Sciences, vol. 92, no. 2, pp. 456-463, 2006.

[99] V. E. Fako and D. Y. Furgeson, "Zebrafish as a correlative and predictive model for assessing biomaterial nanotoxicity," Advanced Drug Delivery Reviews, vol. 61, no. 6, pp. 478-486, 2009.

[100] K. J. Lee, P. D. Nallathamby, L. M. Browning, C. J. Osgood, and $\mathrm{X} . \mathrm{H}$. $\mathrm{Xu}$, "In vivo imaging of transport and biocompatibility of single silver nanoparticles in early development of zebrafish embryos," ACS Nano, vol. 1, no. 2, pp. 133-143, 2007.

[101] O. Bar-Ilan, R. M. Albrecht, V. E. Fako, and D. Y. Furgeson, "Toxicity assessments of multisized gold and silver nanoparticles in zebrafish embryos," Small, vol. 5, no. 16, pp. 18971910, 2009.

[102] J. E. Choi, S. Kim, J. H. Ahn et al., "Induction of oxidative stress and apoptosis by silver nanoparticles in the liver of adult zebrafish," Aquatic Toxicology, vol. 100, pp. 151-159, 2010.

[103] Y. Wu, Q. Zhou, H. Li, W. Liu, T. Wang, and G. Jiang, "Effects of silver nanoparticles on the development and histopathology biomarkers of Japanese medaka (Oryzias latipes) using the partial-life test," Aquatic Toxicology, vol. 100, no. 2, pp. 160-167, 2010.

[104] Y. J. Chae, C. H. Pham, J. Lee, E. Bae, J. Yi, and M. B. Gu, "Evaluation of the toxic impact of silver nanoparticles on Japanese medaka (Oryzias latipes)," Aquatic Toxicology, vol. 94, no. 4, pp. 320-327, 2009.

[105] J. P. Wise, B. C. Goodale, S. S. Wise et al., "Silver nanospheres are cytotoxic and genotoxic to fish cells," Aquatic Toxicology, vol. 97, no. 1, pp. 34-41, 2010.

[106] K. Bilberg, H. Malte, T. Wang, and E. Baatrup, "Silver nanoparticles and silver nitrate cause respiratory stress in Eurasian perch (Perca fluviatilis)," Aquatic Toxicology, vol. 96, no. 2, pp. 159-165, 2010.

[107] T. M. Scown, E. M. Santos, B. D. Johnston et al., "Effects of aqueous exposure to silver nanoparticles of different sizes in rainbow trout," Toxicological Sciences, vol. 115, no. 2, pp. 521534, 2010.

[108] G. Laban, L. F. Nies, R. F. Turco, J. W. Bickham, and M. S. Sepúlveda, "The effects of silver nanoparticles on fathead minnow (Pimephales promelas) embryos," Ecotoxicology, vol. 19, no. 1, pp. 185-195, 2010.

[109] A. H. Ringwood, M. McCarthy, T. C. Bates, and D. L. Carroll, "The effects of silver nanoparticles on oyster embryos," Marine Environmental Research, vol. 69, pp. S49-S51, 2010.

[110] M. Ahamed, R. Posgai, T. J. Gorey, M. Nielsen, S. M. Hussain, and J. J. Rowe, "Silver nanoparticles induced heat shock protein 70, oxidative stress and apoptosis in Drosophila melanogaster," Toxicology and Applied Pharmacology, vol. 242, no. 3, pp. 263-269, 2010.

[111] D. J. Benford, A. B. Hanley, K. Bottrill et al., "Biomarkers as predictive tools in toxicity testing," ATLA Alternatives to Laboratory Animals, vol. 28, no. 1, pp. 119-131, 2000.

[112] E. Bier, "Drosophila, the golden bug, emerges as a tool for human genetics," Nature Reviews Genetics, vol. 6, no. 1, pp. 9-23, 2005. 
[113] R. Wasserkort and T. Koller, "Screening toxic effects of volatile organic compounds using Drosophila melanogaster," Journal of Applied Toxicology, vol. 17, no. 2, pp. 119-125, 1997.

[114] H. R. Siddique, K. Mitra, V. K. Bajpai, K. Ravi Ram, D. K. Saxena, and D. K. Chowdhuri, "Hazardous effect of tannery solid waste leachates on development and reproduction in Drosophila melanogaster: $70 \mathrm{kDa}$ heat shock protein as a marker of cellular damage," Ecotoxicology and Environmental Safety, vol. 72, no. 6, pp. 1652-1662, 2009.

[115] R. Posgai, M. Ahamed, S. M. Hussain, J. J. Rowe, and M. G. Nielsen, "Inhalation method for delivery of nanoparticles to the Drosophila respiratory system for toxicity testing," Science of the Total Environment, vol. 408, no. 2, pp. 439-443, 2009.

[116] S. C. Gupta, A. Sharma, M. Mishra, R. K. Mishra, and D. K. Chowdhuri, "Heat shock proteins in toxicology: how close and how far?" Life Sciences, vol. 86, no. 11-12, pp. 377-384, 2010.

[117] J. Y. Roh, J. S. Sang, J. Yi et al., "Ecotoxicity of silver nanoparticles on the soil nematode Caenorhabditis elegans using functional ecotoxicogenomics," Environmental Science and Technology, vol. 43, no. 10, pp. 3933-3940, 2009.

[118] J. H. Sung, J. H. Ji, J. U. Yoon et al., "Lung function changes in Sprague-Dawley rats after prolonged inhalation exposure to silver nanoparticles," Inhalation Toxicology, vol. 20, no. 6, pp. 567-574, 2008.

[119] Y. S. Kim, J. S. Kim, H. S. Cho et al., "Twenty-eight-day oral toxicity, genotoxicity, and gender-related tissue distribution of silver nanoparticles in Sprague-Dawley rats," Inhalation Toxicology, vol. 20, no. 6, pp. 575-583, 2008.

[120] M. L. Schipper, N. Nakayama-Ratchford, C. R. Davis et al., "A pilot toxicology study of single-walled carbon nanotubes in a small sample of mice," Nature Nanotechnology, vol. 3, no. 4, pp. 216-221, 2008.

[121] Z. Liu, K. Chen, C. Davis et al., "Drug delivery with carbon nanotubes for in vivo cancer treatment," Cancer Research, vol. 68, no. 16, pp. 6652-6660, 2008.

[122] A. Huczko and H. Lange, "Carbon nanotubes: experimental evidence for a null risk of skin irritation and allergy," Fullerene Science and Technology, vol. 9, no. 2, pp. 247-250, 2001.

[123] C.-W. Lam, J. T. James, R. McCluskey, and R. L. Hunter, "Pulmonary toxicity of single-wall carbon nanotubes in mice 7 and 90 days after intractracheal instillation," Toxicological Sciences, vol. 77, no. 1, pp. 126-134, 2004.

[124] D. B. Warheit, B. R. Laurence, K. L. Reed, D. H. Roach, G. A. M. Reynolds, and T. R. Webb, "Comparative pulmonary toxicity assessment of single-wall carbon nanotubes in rats," Toxicological Sciences, vol. 77, no. 1, pp. 117-125, 2004.

[125] A. A. Shvedova, E. R. Kisin, R. Mercer et al., "Unusual inflammatory and fibrogenic pulmonary responses to singlewalled carbon nanotubes in mice," American Journal of Physiology, vol. 289, no. 5, pp. L698-L708, 2005.

[126] P. Cherukuri, C. J. Gannon, T. K. Leeuw et al., "Mammalian pharmacokinetics of carbon nanotubes using intrinsic nearinfrared fluorescence," Proceedings of the National Academy of Sciences of the United States of America, vol. 103, no. 50, pp. 18882-18886, 2006.

[127] M. Davoren, E. Herzog, A. Casey et al., "In vitro toxicity evaluation of single walled carbon nanotubes on human A549 lung cells," Toxicology in Vitro, vol. 21, no. 3, pp. 438448, 2007.
[128] K. Pulskamp, S. Diabaté, and H. F. Krug, "Carbon nanotubes show no sign of acute toxicity but induce intracellular reactive oxygen species in dependence on contaminants," Toxicology Letters, vol. 168, no. 1, pp. 58-74, 2007.

[129] W. Lin, Y. W. Huang, X. D. Zhou, and Y. Ma, "In vitro toxicity of silica nanoparticles in human lung cancer cells," Toxicology and Applied Pharmacology, vol. 217, no. 3, pp. 252-259, 2006.

[130] J.-S. Chang, K. L.B. Chang, D.-F. Hwang, and Z.-L. Kong, "In vitro cytotoxicitiy of silica nanoparticles at high concentrations strongly depends on the metabolic activity type of the cell line," Environmental Science and Technology, vol. 41, no. 6, pp. 2064-2068, 2007.

[131] Y. Jin, S. Kannan, M. Wu, and J. X. Zhao, "Toxicity of luminescent silica nanoparticles to living cells," Chemical Research in Toxicology, vol. 20, no. 8, pp. 1126-1133, 2007.

[132] T. K. Barik, B. Sahu, and V. Swain, "Nanosilica-from medicine to pest control," Parasitology Research, vol. 103, no. 2, pp. 253-258, 2008.

[133] H. Yang, C. Liu, D. Yang, H. Zhang, and Z. Xi, "Comparative study of cytotoxicity, oxidative stress and genotoxicity induced by four typical nanomaterials: the role of particle size, shape and composition," Journal of Applied Toxicology, vol. 29, no. 1, pp. 69-78, 2009.

[134] M. Chen and A. von Mikecz, "Formation of nucleoplasmic protein aggregates impairs nuclear function in response to $\mathrm{SiO}_{2}$ nanoparticles," Experimental Cell Research, vol. 305, no. 1, pp. 51-62, 2005.

[135] F. Wang, F. Gao, M. Lan, H. Yuan, Y. Huang, and J. Liu, "Oxidative stress contributes to silica nanoparticle-induced cytotoxicity in human embryonic kidney cells," Toxicology in Vitro, vol. 23, no. 5, pp. 808-815, 2009.

[136] W. Lin, Y. W. Huang, X. D. Zhou, and Y. Ma, "In vitro toxicity of silica nanoparticles in human lung cancer cells," Toxicology and Applied Pharmacology, vol. 217, no. 3, pp. 252-259, 2006.

[137] D. Lison, L. C. J. Thomassen, V. Rabolli et al., "Nominal and effective dosimetry of silica nanoparticles in cytotoxicity assays," Toxicological Sciences, vol. 104, no. 1, pp. 155-162, 2008.

[138] E. J. Park and K. Park, "Oxidative stress and proinflammatory responses induced by silica nanoparticles in vivo and in vitro," Toxicology Letters, vol. 184, no. 1, pp. 18$25,2009$.

[139] I. Bremner, "Manifestations of copper excess," American Journal of Clinical Nutrition, vol. 67, no. 5, 1998.

[140] D. R. Winge and R. K. Mehra, "Host defenses against copper toxicity," International Review of Experimental Pathology, vol. 31, pp. 47-83, 1990.

[141] D. G. Barceloux, “Copper," Journal Toxicological Clinical Toxicology, vol. 37, no. 2, pp. 217-230, 1999.

[142] G. Liu, X. Li, B. Qin, D. Xing, Y. Guo, and R. Fan, "Investigation of the mending effect and mechanism of copper nano-particles on a tribologically stressed surface," Tribology Letters, vol. 17, no. 4, pp. 961-966, 2004.

[143] N. Cioffi, N. Ditaranto, L. Torsi et al., "Analytical characterization of bioactive fluoropolymer ultra-thin coatings modified by copper nanoparticles," Analytical and Bioanalytical Chemistry, vol. 381, no. 3, pp. 607-616, 2005.

[144] V. N. Bakunin, A. YU. Suslov, G. N. Kuzmina, and O. P. Parenago, "Synthesis and application of inorganic nanoparticles as lubricant components-a review," Journal of Nanoparticle Research, vol. 6, no. 2-3, pp. 273-284, 2004. 
[145] K. Guo, Q. Pan, L. Wang, and S. Fang, "Nano-scale coppercoated graphite as anode material for lithium-ion batteries," Journal of Applied Electrochemistry, vol. 32, no. 6, pp. 679685, 2002.

[146] H. Meng, Z. Chen, G. Xing et al., "Ultrahigh reactivity provokes nanotoxicity: explanation of oral toxicity of nanocopper particles," Toxicology Letters, vol. 175, no. 1-3, pp. 102-110, 2007.

[147] Z. Chen, H. Meng, G. Xing et al., "Acute toxicological effects of copper nanoparticles in vivo," Toxicology Letters, vol. 163, no. 2, pp. 109-120, 2006.

[148] C. M. Galhardi, Y. S. Diniz, L. A. Faine et al., "Toxicity of copper intake: lipid profile, oxidative stress and susceptibility to renal dysfunction," Food and Chemical Toxicology, vol. 42, no. 12, pp. 2053-2060, 2004.

[149] R. Lei, C. Wu, and B. Yang, "Integrated metabolomic analysis of the nano-sized copper particle-induced hepatotoxicity and nephrotoxicity in rats: A rapid in vivoscreening method for nanotoxicity," Toxicology and Applied Pharmacology, vol. 232, no. 2, 2008.

[150] M. Prato, "Fullerene chemistry for materials science applications," Journal of Materials Chemistry, vol. 7, no. 7, pp. 10971109, 1997.

[151] D. Heymann, "Solubility of fullerenes $\mathrm{C}_{60}$ and $\mathrm{C}_{70}$ in seven normal alcohols and their deduced solubility in water," Fullerene Science and Technology, vol. 4, no. 3, pp. 509-515, 1996.

[152] X. Cheng, A. T. Kan, and M. B. Tomson, "Naphthalene adsorption and desorption from aqueous $\mathrm{C}_{60}$ fullerene," Journal of Chemical and Engineering Data, vol. 49, no. 3, pp. 675-683, 2004.

[153] J. D. Fortner, D. Y. Lyon, C. M. Sayes et al., " $\mathrm{C}_{60}$ in water: nanocrystal formation and microbial response," Environmental Science and Technology, vol. 39, no. 11, pp. 4307-4316, 2005.

[154] D. Y. Lyon and P. J. J. Alvarez, "Fullerene water suspension $\left(\mathrm{nC}_{60}\right)$ exerts antibacterial effects via ROS-independent protein oxidation," Environmental Science and Technology, vol. 42, no. 21, pp. 8127-8132, 2008.

[155] S. B. Lovern and R. Klaper, "Daphnia magna mortality when exposed to titanium dioxide and fullerene $\left(\mathrm{C}_{60}\right)$ nanoparticles," Environmental Toxicology and Chemistry, vol. 25, no. 4, pp. 1132-1137, 2006.

[156] S. Zhu, E. Oberdörster, and M. L. Haasch, "Toxicity of an engineered nanoparticle (fullerene, $\mathrm{C}_{60}$ ) in two aquatic species, Daphnia and fathead minnow," Marine Environmental Research, vol. 62, no. 1, pp. S5-S9, 2006.

[157] A. Dhawan, J. S. Taurozzi, A. K. Pandey et al., "Stable colloidal dispersions of $\mathrm{C}_{60}$ fullerenes in water: evidence for genotoxicity," Environmental Science and Technology, vol. 40, no. 23, pp. 7394-7401, 2006.

[158] K.-T. Kim, M.-H. Jang, J.-Y. Kim, and S. D. Kim, "Effect of preparation methods on toxicity of fullerene water suspensions to Japanese medaka embryos," Science of the Total Environment, vol. 408, no. 22, pp. 5606-5612, 2010.

[159] P. Hoet and J. Boczkowski, "What's new in nanotoxicology? Brief review of the 2007 literature," Nanotoxicology, vol. 2, no. 3, pp. 171-182, 2008.

[160] R. F. Service, "Nanotechnology grows up," Science, vol. 304, no. 5678, pp. 1732-1734, 2004.

[161] M. R. Gwinn and V. Vallyathan, "Nanoparticles: health effects-pros and cons," Environmental Health Perspectives, vol. 114, no. 12, pp. 1818-1825, 2006.
[162] J. K. Nicholson, J. Connelly, J. C. Lindon, and E. Holmes, "Metabonomics: a platform for studying drug toxicity and gene function," Nature Reviews Drug Discovery, vol. 1, no. 2, pp. 153-161, 2002.

[163] H. J. Atherton, N. J. Bailey, W. Zhang et al., "A combined $1 \mathrm{H}-\mathrm{NMR}$ spectroscopy- and mass spectrometry-based metabolomic study of the PPAR- $\alpha$ null mutant mouse defines profound systemic changes in metabolism linked to the metabolic syndrome," Physiological Genomics, vol. 27, no. 2, pp. 178-186, 2006.

[164] E. J. Want, A. Nordström, H. Morita, and G. Siuzdak, "From exogenous to endogenous: the inevitable imprint of mass spectrometry in metabolomics," Journal of Proteome Research, vol. 6, no. 2, pp. 459-468, 2007.

[165] M. L. Anthony, K. P. R. Gartland, C. R. Beddell, J. C. Lindon, and J. K. Nicholson, "Cephaloridine-induced nephrotoxicity in the Fischer 344 rat: proton NMR spectroscopic studies of urine and plasma in relation to conventional clinical chemical and histopathological assessments of nephronal damage," Archives of Toxicology, vol. 66, no. 8, pp. 525-537, 1992.

[166] K. P. R. Gartland, C. R. Beddell, J. C. Lindon, and J. K. Nicholson, "Application of pattern recognition methods to the analysis and classification of toxicological data derived from proton nuclear magnetic resonance spectroscopy of urine," Molecular Pharmacology, vol. 39, no. 5, pp. 629-642, 1991.

[167] E. Holmes, A. W. Nicholls, J. C. Lindon et al., "Chemometric models for toxicity classification based on NMR spectra of biofluids," Chemical Research in Toxicology, vol. 13, no. 6, pp. 471-478, 2000.

[168] C. J. Waterfield, J. A. Turton, M. D. C. Scales, and J. A. Timbrell, "Investigations into the effects of various hepatotoxic compounds on urinary and liver taurine levels in rats," Archives of Toxicology, vol. 67, no. 4, pp. 244-254, 1993.

[169] D. G. Robertson, M. D. Reily, R. E. Sigler, D. F. Wells, D. A. Paterson, and T. K. Braden, "Metabonomics: evaluation of nuclear magnetic resonance (NMR) and pattern recognition technology for rapid in vivo screening of liver and kidney toxicants," Toxicological Sciences, vol. 57, no. 2, pp. 326-337, 2000.

[170] N. J. Waters, C. J. Waterfield, R. D. Farrant, E. Holmes, and J. K. Nicholson, "Integrated metabonomic analysis of bromobenzene-induced hepatotoxicity: novel induction of 5-oxoprolinosis," Journal of Proteome Research, vol. 5, no. 6, pp. 1448-1459, 2006.

[171] S. Parvez, C. Venkataraman, and S. Mukherji, "A review on advantages of implementing luminescence inhibition test (Vibrio fischeri) for acute toxicity prediction of chemicals," Environment International, vol. 32, no. 2, pp. 265-268, 2006.

[172] A. P. Loibner, O. H. J. Szolar, R. Braun, and D. Hirmann, "Toxicity testing of 16 priority polycyclic aromatic hydrocarbons using Lumistox," Environmental Toxicology and Chemistry, vol. 23, no. 3, pp. 557-564, 2004.

[173] J. Lappalainen, R. Juvonen, J. Nurmi, and M. Karp, “Automated color correction method for Vibrio fischeri toxicity test. Comparison of standard and kinetic assays," Chemosphere, vol. 45, no. 4-5, pp. 635-641, 2001.

[174] H. Zheng, L. Liu, Y. Lu et al., "Rapid determination of nanotoxicity using luminous bacteria," Analytical Sciences, vol. 26, no. 1, pp. 125-128, 2010. 


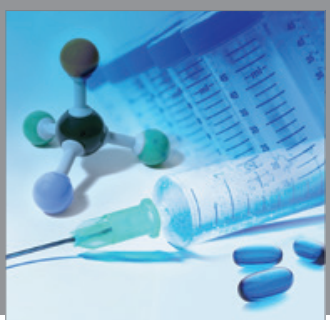

International Journal of

Medicinal Chemistry

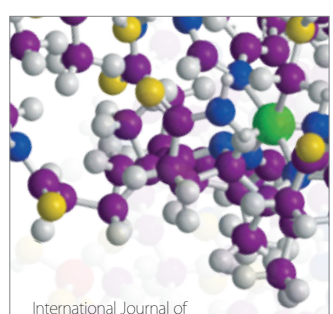

Carbohydrate Chemistry

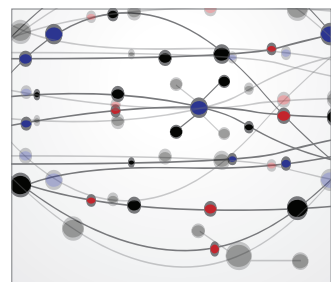

The Scientific World Journal
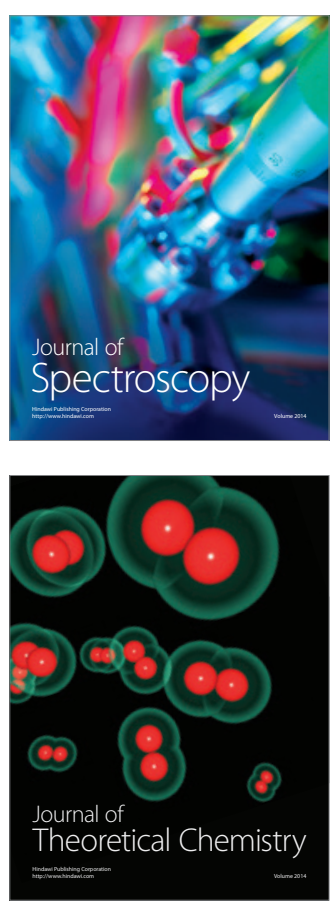
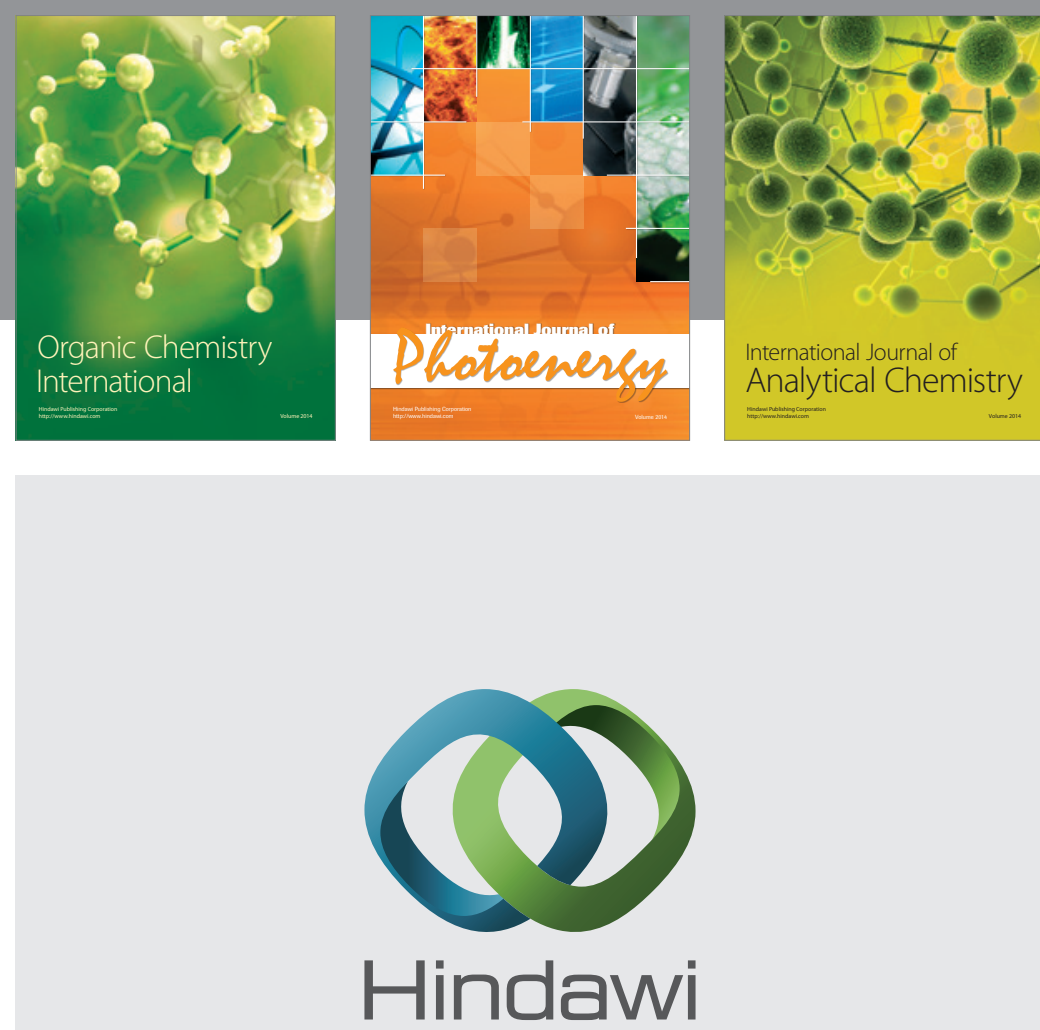

Submit your manuscripts at

http://www.hindawi.com
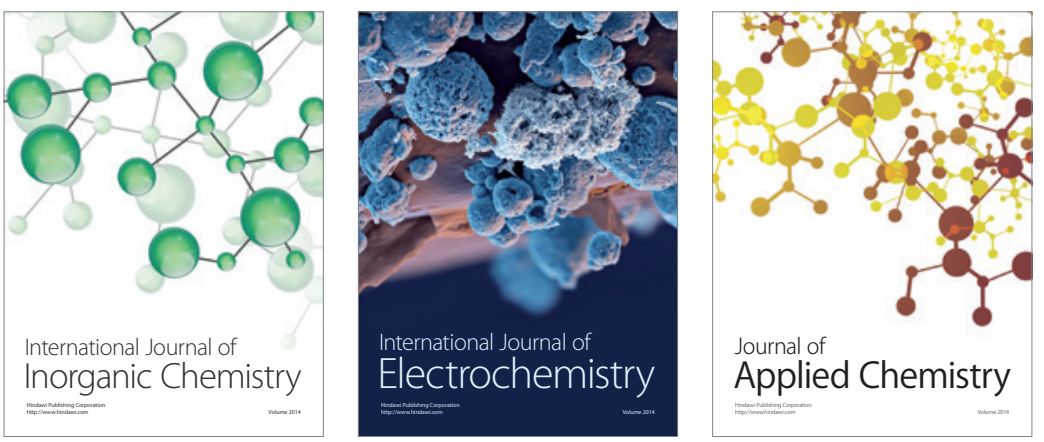

Journal of

Applied Chemistry
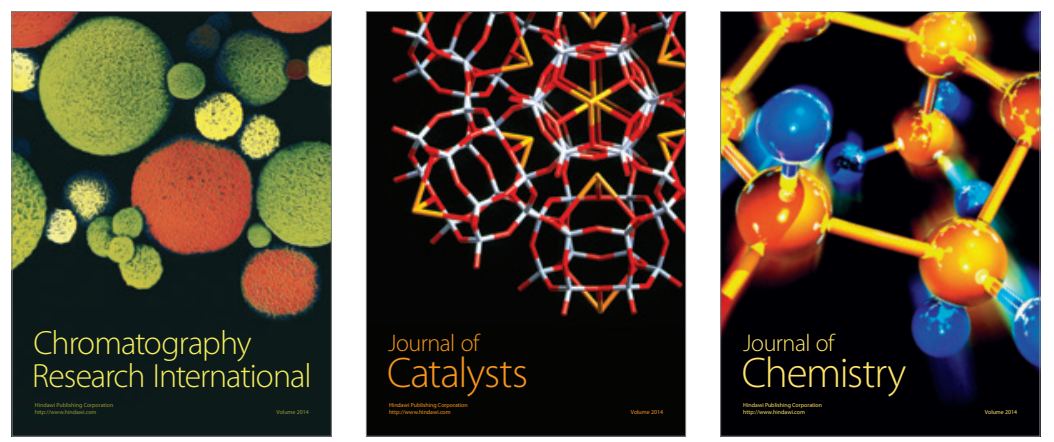
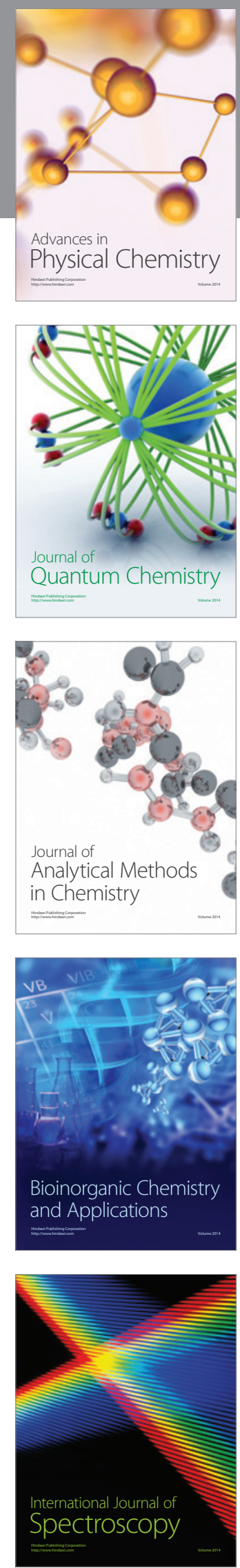